\title{
EL SUEÑO DE LA CODIFICACIÓN Y EL DESPERTAR DEL DERECHO
}

\author{
M. Leonor Suárez Llanos \\ Universidad de Oviedo
}

RESUMEN. Una parte importante de este trabajo centra su interés en mostrar, desde una perspectiva iusfilosófica, los problemas y obstrucciones de los que adolece la codificación en las sociedades y órdenes sociales postindustriales y postmodernos contemporáneos. En este sentido, el interés del análisis se centra en la "crisis" de la codificación que aquejaría a los Estados legicéntricos. Una crisis vinculada al impacto de la alianza Estado-sociedad y la conformación de un nuevo modelo neoconstitucional del Estado social de Derecho. En este marco, la codificación ya vería frustrada su fundamental función práctica de reducir la complejidad social. El siguiente paso nos conduce al objeto fundamental de interés de este trabajo, mostrar en qué sentido un nuevo modelo de codificación es posible. En este sentido, propondré un modelo de neocodificación centrado en un concepto del Derecho comprehensivo, plural y dinámico orientado a una neocodificación abierta y "a Derecho constante".

Palabras clave: Crisis de la codificación, neocodificación.

ABSTRACT. An important part of this paper is interested in showing, from an iusphilosophical perspective, the problems and obstructions of codification in the contemporary era in the postindustrial and "postmodern" societies and social orders. In this sense, the interest of this analysis focuses on the "crisis" of codification in statute-centered countries. A crisis related to the impact of the alliance state-society for conforming a new model of neoconstitutional social Rule of Law (state of Law) in which codification fails its fundamental practical function of reducing social complexity. The next step leads us to the fundamental object interest of this paper, to show in which sense a new model of codification is possible. In this sense, I will propose a model of neocodification centered in a comprehensive, plural and dynamic concept of Law which leads to a neocodification opened and "to constant Law".

Keywords: Crysis of Codification, Neocodification. 


\section{$(1)$}

A lo largo de las décadas la codificación ha ido perdiendo muchas de sus buenas razones presionada, en amplia medida, por la conciencia de que la complejidad y dinamicidad de las relaciones sociales difícilmente puede encapsularse en un momento de inspiración legislativa. Por eso, será bueno cuestionarse si, razonablemente, eso que el Código haya perdido, podrá ahora ganarlo en razón o si ésta recomienda romper el compromiso codificador.

(2) La segunda mitad del siglo Xx marca el inicio de una revolución jurídica contra el formalismo y el cientifismo instaurados en el siglo XIX y contra el proyecto mismo del Estado de Derecho. En la convulsión de esta revolución, en la que estamos más menos cómodamente instalados, determinar en qué consiste el Derecho se ha convertido en una cuestión relativa dependiente de distintas claves que centraré en torno a dos posiciones.

La una, escéptica y abanderada de una postmodernidad, que ya viene de antiguo, y que cuestiona la fe racional en la teoría positivista del Derecho y en la concepción política liberal sobre la que se erige. En torno a esta comprensión giran distintas variantes que se radicalizan en un "deconstructivismo" (vinculado a los CLS); los valores político-liberales encubren la voluntad de dominación y la teoría y doctrina del Derecho la legitiman mostrando su carácter esencialmente contradictorio y variable (MANGABEIRA UNGER). Consecuentemente, el reclamo es desarticular el conjunto de categorías que operan en la doctrina legal, falsamente enmascaradas de racionalidad, para desactivar las fuerzas político-económicas que actúan ilegítimamente como factores de opresión.

La segunda alternativa de comprensión del Derecho se opone a la anterior al vincularse al optimismo de la apología de los valores liberales y al ideal de racionalizar el instrumental jurídico sistematizándolo en cuerpos coherentes que fijen la actividad discrecional del juez, la razón democrática encapsulada en la voluntad legislativa, la seguridad jurídica y la conceptualización jurídica general. Aunque también abraza distintas versiones, esta alternativa se homogeneiza en la especulación y la práctica que formatea el registro teórico de los operadores jurídicos en gran parte de las sociedades jurídicas desarrolladas desde el siglo XIX: exaltación de la Constitución organizativa y procesual, definición de un legislador presuntamente racional, de un aparato ejecutivo- administrativo que desarrolla la ley positiva y de una red judicial que "sólo" aplica la ley. La cima del proyecto se abandera con la institucionalización codificadora y la lógica estatista exegética de la aplicación judicial que recorre la Europa continental y América del Sur.

Si el problema de la primera alternativa es su vacío constructivo, el deconstructivismo al que aboca su convencimiento de que la teoría y la práctica demuestran la irracionalidad política y la manipulación trasunta en la promesa de racionalización del Derecho y, por lo que aquí más me interesa, en la codificación, a la segunda, contemplada desde la perspectiva de esta codificación, cada vez se le hace más difícil ocultar su frustración y el carácter frustrante de su utópico proyecto y de su fe en el progreso racional y en la posibilidad de encapsular en un instante de voluntarismo legislativo la realidad político-social dada y por venir. 


\section{SOBRE INTROMISIONES IUSFILOSÓFICAS EN UNA CONCEPCIÓN DOGMÁTICA}

(3) Los Códigos que tratan de vertebrar la juridicidad de la mayoría de los Estados desarrollados se elaboraron como instrumentos positivos al servicio de la voluntad de un legislador mítico sostenido por un ideario fantástico que justificaría pretensiones "extraordinarias" alejadas del mundanal ruido de los intereses particulares y de la malla de relaciones de una sociedad cambiante y conflictiva. El Código estaría más allá de lo contingente, es lo necesario, el criterio regulador excelente que permanece aunque se cuestionen todas las piezas del Derecho. Y es que, con él, la arbitrariedad de la voluntad subjetiva del legislador se autotrasciende hasta alcanzar la racionalidad que legitima la iurisperita facultad para pedir y aplicar el Derecho.

Y, puede decirse mucho más; que la codificación vuelve al Derecho más comprensible, claro y accesible a los operadores jurídicos y a los ciudadanos, que lo unifica, que posibilita su articulación lógica y así su manejo, que facilita su reforma, etc.

Pues bien, lo que me interesa saber es, de un lado, si esos predicamentos son ciertos y aun defendibles. Y, de otro, si buscando respuestas es legítimo cuestionar iusfilosóficamente la racionalidad codificadora, como aquí se pretende, o si el empeño sólo puede alentar un criticismo ensimismado en categorías fantasmales sin anclaje ni operatividad práctica; ¿no debería reservarse el análisis de la codificación a la dogmática, a la comprobación de su posibilidad por los operadores prácticos, a su casación constitucional por el constitucionalista y a su descripción acrítica como fuente-producto del Derecho por el teórico del Derecho?

(4) Al respecto, tomaré el siguiente punto de partida: la dogmática del Código trascendió sus propios contenidos hasta engendrar una tradición ideológica de resistencia que consolidó una mística enclaustrante en una presunción fuerte de racionalidad. Y es que se elevó una pieza del Derecho, el Código, a elemento basal de la razón, justicia, seguridad y continuidad de ese Derecho. Por tal razón, la cuestión codificadora interesa y mucho a la visión conocedora (participante-interna) pero distanciada (desvinculada) que propone la crítica iusfilosófica. Y ya no por reclamar una función nocorrespondiente, sino por la necesidad de segmentar críticamente - con un instrumental descreído de realimentaciones en tradiciones fundamentadas en el uso de la voluntadlos arquetipos codificadores, a fin de desenmarañar su presunta racionalidad en los filamentos de razón que aún puedan urdir sus mimbres, si es que algo queda de esa razón. Esta legitimidad iusfilosófica y el correspondiente interés crítico, a su vez, exigen indagar en los presupuestos racionales y las posibilidades racionalizadoras del modelo iuspositivo codificador en el marco neoconstitucional en el que estamos inmersos.

Pues bien, en este contexto, parto del siguiente planteamiento general. El Derecho no es sólo un orden de coacción, por mucho que la sociedad se engrane sobre la interpretación de su carácter coactivo - la norma no es un objeto o hecho discernible de otros porque pueda ser arrojado por el legislador a los operadores jurídicos para que sientan su fuerza coactiva-. Más bien, y/o también, el Derecho integra un sistema particular de comunicación que actúa en la sociedad reduciendo la complejidad de las situaciones. Por supuesto que el Derecho y las normas tienen que ver con los hechos evidenciándose su relación recíproca, pero también su diferencia, pues el verdadero 
hecho del Derecho es la distinción hecho/norma ${ }^{1}$; lo jurídicamente válido y normativo no es lo que deba ser válido, sino lo que lo es en virtud de una interacción comunicacional que da sentido a una normatividad que se autodiferencia de los hechos mismos.

(5) A partir de aquí, lo que planteo es que el sistema comunicacional que dio sentido normativo a la codificación ha sufrido una transgresión de sus claves comunicacionales, lo que lleva a cuestionar la normatividad de un Código que se engrana en un metadiscurso legitimador que ya ha perdido buena parte de su credibilidad pragmática. ¿Por qué? Por la proliferación de la legislación especial atenta a intereses particulares, por la fuerza directa de la Constitución material, por la influencia del Derecho supranacional y comunitario; por el aumento de la discrecionalidad judicial; por el efecto cascada de la valoración que acompaña a los principios constitucionales, etc. En tal marco jurídico de comunicación el Código habría perdido su capacidad para cumplir la finalidad, que un día le diera sentido, de reducir la complejidad comunicacional del mundo de los hechos.

Por todo ello, me parece que lo que procede es procurar un alejamiento que garantice la suficiente abstracción respecto de la práctica de «cómo entienden y cómo manejan los juristas...» el Derecho codificado para descubrir qué es lo que se gana y se pierde con la codificación.

En concreto, la cuestión es si la codificación genera un modelo de comunicación normativo aun hoy suficientemente operativo y si es adecuado (perspectivas sociológica, crítica y valorativa) rehabilitar y adecuar sus claves normativas a las exigencias comunicacionales de la sociedad en relación con el subsistema jurídico, si debe considerarse un instrumento residual y reductivo referido a lo no regulado por el actual y expansivo sistema normativo o si, en realidad, habría que dejar de considerarla como un modo de expresión legislativo (GARCÍA CANTERO).

\section{EL VIAJE CODIFICADOR POR LA LEGISLACIÓN}

(6) La fundamentación y el carácter fundamental de la codificación se vinculan a su papel enaltecedor de la ley, instrumento esencial de constitución y actuación del Derecho.

El Estado moderno, en conjunción con su definición soberana, suprema potestas, se caracterizó como es bien sabido por el reclamo de centralización del poder, la sumisión a la voluntad de ese poder, esto es, a la ley, y la consagración de los presupuestos de la racionalización y secularización de la política y la legislación. Ahora «las leyes no se mantienen porque sean justas, sino porque son leyes. Es el fundamento místico de su autoridad ${ }^{2}$; no tienen otro fundamento y es bastante. Con frecuencia están hechas por necios» (MONTAIGNE).

Sin embargo, enseguida se constata que una parte del planteamiento vale, pero otra no. Y esto impulsa la transformación del concepto moderno de Estado de los

\footnotetext{
1 Al respecto y complementariamente, LUHMANN, 2002: 87-88.

2 «La mística de la ley, la mística de la ley en cuanto ley, (es) una herencia del absolutismo regio que la revolución del finales del Setecientos asume sin pestañear, intensificándola y endureciéndola» (GROSSI, 2003: 32).
} 
siglos XIV a XVII al concepto de Estado de Derecho liberal. Y es que la centralización del poder necesario para dotar de una significación homogénea y autoritativa a la ley encubre un fuerte elemento dictatorial - lo destacaron BENTHAM, TOCQUeVILle, ACTON, RENAN,...- opuesto al germen individualista, humanista y de libertad desarrollado durante el Renacimiento.

(7) Sobre estas bases, sistematizaré el recorrido de la teoría legislativa que comprime el concepto moderno de la ley y que da sentido al proyecto codificador en tres sucesivas etapas.

La primera centrada en el Estado absoluto en el que el derecho de legislar depende sólo de la voluntad del soberano - lo sistematizaba ARNISAEUS en su teoría de los iura majestatis.

La segunda etapa se corresponde con el fortalecimiento y victoria de la filosofía política liberal que impugnó la fuerte tendencia dictatorial de una legislación voluntarista redefiniendo el par libertad-autoridad que, ya lo sabía HoBBES, concreta la experiencia política del hombre. Lo que se busca es la liberación de las leyes despóticas y de la creencia en que su sola proliferación, como pensara HEGEL, haría al individuo más libre. Esa liberación exigiría la protección legal de los derechos, libertades y garantías liberales y la institucionalización del modelo democrático-liberal. El proyecto codificador arranca en esta segunda etapa de la teoría de la legislación, prometiendo al ideario racionalista el instrumento jurídico positivo que dotase del más alto rango de racionalidad formal a la razón material ilustrada. Las leyes habrían de ser los átomos a estructurar en un cuerpo compacto de ordenación y de relaciones armónicas, y tal era el objetivo del Código - ofrecer un cierre positivo, perfecto, racional, sistemático, único, unitario, completo y armónico al Derecho ${ }^{3}$ - Sin embargo, las cosas no resultaron tan sencillas.

La tercera etapa de la teoría legislativa se inicia tras la II Guerra Mundial con la conversión del Estado de Derecho en Estado social. Este giro cambia el signo de la legislación en un esfuerzo por satisfacer las demandas generales y particulares de justicia y la especificidad de los intereses. Aunque también anima conflictivas consecuencias: inflación legislativa, fuertes oleadas principialistas amparadas en el marco neoconstitucional, crisis de la seguridad jurídica y quiebra (¿definitiva?) del orden racional y racionalizador del Derecho. Es en este marco en el que la codificación parece haber perdido ya gran parte de su sentido, virtud y funcionalidad.

\section{CONSISTENCIA DEL VIEJO PROYECTO CODIFICADOR}

\section{1. (8) La razón, la ideología y la técnica de la codificación}

El proyecto codificador napoleónico constituye la primera codificación moderna al responder a las exigencias ilustradas de un ideal racional ${ }^{4}$ que impone «un cambio

\footnotetext{
3 Complementariamente, De los Mozos, 2001: 2, De los Mozos, 1988: 637 y ss.

${ }^{4}$ Que concretaría, bajo inspiración de un KANT, que seguía a LEIBNIZ y DESCARTES, que la racionalidad consiste en «completar... la conexión sistemática mediante el ascenso a los géneros superiores y el descenso a
} 
en el modo de formalización del Derecho» (MonTiLla 1987: 547) conformado a los principios racionales de sistematización, completud, estatalidad, soberanía legislativa codificada, perfecta delimitación del sistema de fuentes y ruptura con un pasado -el del antiguo y arbitrario droit coutumier - que Napoleón I repudiaba. Ya no se trataría de recopilar o reformular el Derecho existente, sino de planificar la sociedad con nuevas ordenaciones sistemáticas y creadoras ${ }^{5}$-aunque en muchos casos no se alteró materialmente en lo sustancial el Derecho previo a la codificación ${ }^{6}-$. Así, el proyecto codificador se enfrente al caos político-jurídico del Antiguo Régimen elevando un sistema nomológico perfecto garante de la sencillez, la coherencia, la plenitud, la unidad y, por tanto, de la seguridad y libertad al ciudadano al liberarle de los fueros, servidumbres, limitaciones, prejuicios... que le acompañaron en el Antiguo Régimen (CONSTANT).

Sin embargo, la plasmación positiva codificada de tan altos ideales impuso ciertos ajustes tendenciosos. Porque aunque formalmente apelaba al proyecto liberal triunfante y al conjunto de contenidos constitucionales de lo que después se denominará Estado de Derecho, lo que positivizó fue: 1) una separación de poderes más conforme a la influencia rousseauniana que a la de MONTESQUIEU que condujo a la supremacía de la ley y a la omnipotencia del legislador frente a cualquier posibilidad de control constitucional o judicial (y supresión del ius vetum), al representar el legislador la soberanía popular conforme a un modelo democrático - doctrinalmente titubeante y que al final, materialmente, impuso un criterio censitario (varón propietario)—; 2) un ejecutivo administrativamente centralizado; 3 ) un poder judicial ya independiente del ejecutivo pero servilmente subordinado al legicentrismo imperante.

A esto debe añadirse que, en realidad, positiva y materialmente, la codificación sirvió a la pretensión de la nueva clase burguesa - fracturar la propiedad nobiliaria y la base material del poder aristocrático- para garantizar la seguridad en el desarrollo de su actividad y de su propiedad, margen privado inatacable de cada individuo (LOCKE). Por eso la institución de la propiedad se codificó en términos muy amplios, libre de cargas y sometida a unas limitaciones legales que debían interpretarse restrictivamente. Esto ayuda a entender por qué la libertad del pueblo se codifica como la libertad para contratar y ser contratado (libertad para el "acuerdo de voluntades") y para ser titular de patrimonio, y por qué la propiedad, factor esencial de la actividad económica, se convierte en el eje del sistema jurídico y de las relaciones contractuales y hereditarias. El problema fue que la protección codificadora del modelo capitalista propietario llevó a limitar materialmente los derechos de la mayor parte de la sociedad ${ }^{7}$.

las especies inferiores»; sistematizar el conocimiento es ponerlo en «su interconexión a partir de un solo principio» —al respecto y complementariamente, HORKHEIMER, ADORNO, 1994: 129 y ss.

5 Al respecto, WIEACKER, 1957: 292-293.

${ }^{6}$ Complementariamente, De Los Mozos, 1988: 666-667, y Vargas Muñoz, 2003: 762-763.

7 El sueño de la Convención de una codificación impulsada por la colaboración de juristas y filósofos se disuelve con la presión de la realidad. Tras los tres proyectos de codificación rechazados de Cambacérès (1793, 1794, 1796) ya no gobiernan los jacobinos (anhelantes de un Código de principios filosóficos) y se impone una tendencia crecientemente conservadora que revisa toda la legislación dictada por la Convención Nacional. Sólo cuando se instaura el gobierno fuerte de Napoleón se posibilita la codificación desarrollada fundamentalmente por juristas. 
Por otra parte, tampoco debe olvidarse la ideología política centralista y nacionalista propia a la pretensión codificadora de acabar con la diversidad jurídica. De tal modo que, so excusa de suprimir la dispersión ${ }^{8}$, se anuló toda diferencia político-territorial contraria a la centralidad del Estado?.

La centralización y exaltación de la ley que todo este proyecto codificador impulsa demostró su vigorosa fuerza centrífuga y centrípeta exhibiendo sus alianzas técnicoformales con un modelo legislativo ${ }^{10}$ que cerraba materialmente la presunción de racionalidad legislativa.

La fuerza centrífuga o excluyente de la conversión de la ley en el pivote esencial de creación y desarrollo del Derecho determinó, de un lado, que en la Europa continental las Constituciones liberales se consideraran textos programáticos a los que el legislador formalmente democrático y así presuntamente racional, consecuentemente, no debía ninguna pleitesía. Y, de otro lado, que se limitase al extremo la relevancia de la costumbre ${ }^{11}$, «regla inconveniente e ilegítima por la que sólo deben gobernarse los animales» (BENTHAM).

Pero no importaba sólo limitar y excluir sino también incluir y afirmar normativamente las condiciones técnicas necesarias para la exaltación de la racionalidad legislativa. Así, se apuntala el ideal legicéntrico codificador proyectando que $\left.{ }^{12}: 1\right)$ el Derecho, todo el Derecho y el único Derecho, es el Derecho positivizado en la codificación-; 2) la codificación no expresa un sumatorio de normas, sino un modelo de racionalización, organización y ordenación perfecta que no precisa, ni consiente, el recurso a ninguna fuente ajena al Código. Para alcanzar el modelo racional exclusivo y excluyente del Código, las normas jurídicas, las leyes que materializa deben ser; 3 ) generales y abstractas; 4) claras y precisas; 5) sencillas, permanentes y comprensibles; 6) racionales, es decir, formalmente adaptadas a la lógica en sus distintas manifestaciones; 7) exhaustivas, porque deben regular todas las manifestaciones de la realidad sin que nada quede fuera de su alcance; 8) como consecuencia sistémico racional, se concreta exegéticamente la absoluta dependencia de la jurisdicción al modelo legislativo codificado, de tal forma que el Derecho de los juristas, el ius commune, y la creación jurisprudencial de la interpretatio doctorum se rinden sin concesiones al poder de la ley.

${ }^{8}$ El ancien droit francés que precede a la Revolución se caracterizaba por su diversidad. Dividida Francia en las dos grandes demarcaciones del norte —en la que regían las coutumes influencias por el Derecho germánico- y el sur —en la que aplicaba como droit écrit principalmente el Derecho romano aunque también las costumbres-, se constataba una diversidad y un tratamiento no igualitario que fomentaba la inseguridad jurídica ya impugnada por distintas voces prerrevolucionarias. De hecho las Ordenanzas de D'Aguesseau reglamentan de forma unitaria amplias instituciones civiles y sus disposiciones en parte pasaron al Código Civil de 1804.

9 Así, se suprimirían las particularidades locales —y en España el modelo foral— «para coadyuvar al dogma del Estado como pieza clave de la organización política» (HERNÁNDEZ GiL) propiciando la idea del Estado nacional (basado en una misma lengua, las mismas instituciones y el mismo Derecho en toda la nación).

${ }_{10}$ Se construye al "legislador" como un sujeto codificador trascendental «que, en lugar de ser aquel de carne y hueso con su voluntad, se ideó como un ente abstracto dotado de una razón que va del legislador concreto al "legislador bueno"» (TARELLO, 1995: 46).

${ }_{11}$ Complementariamente, Alejandre GarCía, 1980: 135 y ss.

12 Véase, complementariamente, Cazorla PRIETO, 1999: 28-29. 


\section{2. (9) La teoría del Derecho y la codificación}

La victoria positiva y expansiva de la codificación decimonónica marca el signo legalista, legiferante y dogmático de los siglos XIX y XX.

Ya al desnudo la dimensión voluntarista de la legislación, la racionalidad superviviente del Derecho fue urdida por el proyecto codificador: había que sistematizar conforme a claves de autoenclaustramiento. Por eso, conocer el Derecho y manejarlo mejor pasó a significar elaborar una descripción objetiva de su realidad voluntarista positiva ${ }^{13}$; empresa esta en la que se embarcaron la dogmática y la teoría general del Derecho (TGD) del siglo XIX y primera mitad del $\mathrm{XX}^{14}$ para rubricar, bajo la influencia de los positivismos filosófico y científico, la perfección nomológica de la estructura lógicodeductiva y geométrica en que se convierte la legislación.

La racionalidad científica con que se quiso definir el Derecho se autodelimitó por contraste con la irracionalidad política y axiológica, lo que ratifica la reducción de la ley a mera voluntad y consagra la racionalidad formal, positiva, científica y lógica como único modelo de teorización y descripción del Derecho. De este modo, el legicentrismo que exaltaba el ideal práctico codificador y el análisis teórico del Derecho (no práctico, ni hipotético) centrado en la descripción de la legislación omniscente, omnipotente y positiva, encajaron perfectamente en su afán de seguridad, objetividad y rigor del conocimiento científico ${ }^{15}$.

Por ello, y como epistemológicamente la TGD radicaliza su pretensión de pureza metodológica en torno a las condiciones de corrección y sistematicidad al margen de otras vías o caminos improbables, se convirtió en la fundamentación teórica perfecta de una codificación que, a la par, le ofrecía el presupuesto positivo más perfecto a su esfuerzo especulativo ${ }^{16}$.

Sin embargo, desde mediados del siglo XX, el planteamiento cientifista que se colgaba del árbol de la razón nomológica es zarandeado por múltiples ráfagas críticas ${ }^{17}$ : la fe en el proceso lógico-deductivo y subsuntivo demostró su exceso y error y su tendencia a enmascarar, en la forma y la lógica, la ilógica y la arbitrariedad judicial, mientras que la especulación propia de la TGD da cuenta de sus contradicciones y defectos y de los efectos político-jurídicos de su ideología valorativa de la certeza y la neutralidad descriptiva. En este marco especulativo, hasta entonces pertrechado frente

13 En este sentido y complementariamente, MARCILla CóRDOBA, 2005: 113 y ss.

14 Atiéndase a IHERING, 1961: 237.

15 Así, «(e)l positivismo jurídico emprendió el camino de la logicización (Logisierung) de la teoría jurídica del Estado... mediante la formación de conceptos antitéticos cuya contraposición lógica permitirá resolver... cuestiones fundamentales sin recurrir a valoraciones» (LUCAS VERDÚ, 1987: 209).

${ }_{16}$ En este mismo sentido, PREUSs, 1986: 158.

17 Diría que como una culminación de las críticas que desde el siglo XIX fortalecen las corrientes antiformalistas; una «revuelta contra el formalismo jurídico» (WHITE) que acusa la irracionalidad legal reclamando, a la par, el papel creciente de la jurisdicción como renuncia al silogismo propio al voluntarismo legislativo. El segundo IHERING — representativamente con las Cartas sobre la jurisprudencia actual»—, HECK — que destaca la incapacidad e imposibilidad legislativa y de la legislación (al respecto, HECK, 1999: 30)—, GÉNY —enfrentado al «fetichismo de la ley y escrita y codificada» (GÉNY, 2000: 53)—, DUGUIT — con El Pragmatismo Jurídico-, los defensores del Derecho libre, representativamente KANTOROWICZ — con «La lucha por la ciencia del Derecho»-, luego el realismo y su concepción incendiariamente indiciaria de la ley, la tópica, la hermenéutica, las teoría de la argumentación..., son representativos al respecto. 
a toda concepción político-valorativa, la brecha pragmática que se abre en el nivel de la jurisdicción se irá extendiendo, animada por la vieja "cuestión social" y la praxis del nuevo Estado social neoconstitucional y su amplia panoplia de derechos y principios, hasta alcanzar el dominio de la teorización positivista. Así, a partir de la segunda mitad del siglo XX se objeta generalizadamente la pretenciosidad e incapacidad cientifista de la TGD y la Metodología del Derecho y comienza a teorizarse sobre una profunda crisis de la ley, del Derecho, del legislador, de la Constitución, etc., que alerta de que el Derecho ya habría pasado a actuar al margen de los criterios de legalidad presupuestos.

\section{3. (10) La teoría de la legislación y el Código}

Lo anterior ayuda a entender por qué la teoría de la legislación moderna "desaparece” con la iuspositivización decimonónica y la eclosión de la TGD. Pero, también, que reaparezca en el último tercio del siglo $\mathrm{xx}$ - y tenga por "pionera" la obra de Noll (Gesetzgebungslehre) de 1973 - cuando la praxis político-jurídica posibilita un análisis más amplio, ambicioso y pragmático que introduce perspectivas críticonormativas y valorativas respecto de la legislación:

Tras la victoria de la concepción política liberal el interés por la ley se acrecentó —-segunda etapa de la teoría de la legislación — frente al análisis de la teoría del Estado moderno y absolutista. Y es que la ley pasó a contemplarse como un instrumento fundamental al servicio de la igualdad, la libertad y el derrocamiento del Antiguo Régimen. Precisamente por eso se pueden recontar en MONTESQUIEU (y El Espíritu de las Leyes), en Filangieri (y La Ciencia de la Legislación), en Bentham (y su Tratado de Legislación Civil y Penal, su Falacias Políticas, Tácticas Políticas y su Nomografía) o en Austin (en su Province of Jurisprudence Determinated) ${ }^{18}$ los prolegómenos de la teoría de la legislación.

Sin embargo, la realidad teórica y práctica iuspositivista de los siglos XIX y XX no tardó en mostrar su escasa fidelidad al ideario político que le diera sentido, y conso-

18 BENTHAM y AUSTIN son claros partidarios de realizar una apropiada codificación, especialmente en un país en el que impera un sistema de common Law que abre un amplio margen de discrecionalidad y decisionismo judicial. BENTHAM enfrenta una fuerte crítica al sistema de common Law inglés por su absoluta asistematicidad y carencia de una línea uniforme de desarrollo legislativo —e imposibilidad de ello- al estar en manos de la formulación judicial. Incluso llegó a proyectar una especie de Digesto de Derecho inglés que incorporaría sistemáticamente reglas constituyentes y principios fundamentales de su Derecho. Finalmente, proyecta una reforma radical del Derecho a través de una completa codificación. Y Austin califica el Derecho judicializado inglés de «caos monstruoso» que debe ser sustituido por una forma superior de entenderlo, dotada de estructura y de sistematicidad, esto es, de una codificación que representa, para AusTIN, la última fase del desarrollo histórico del Derecho en la sociedad.

En el ámbito alemán el panorama se enturbia con la tensión entre el historicismo y las pretensiones codificadoras. Entre las muchas agitaciones provocadas en Alemania por la ocupación napoleónica, se produjo también un movimiento favorable a un Derecho único y codificado para toda Alemania (extendiendo la aplicación del Código de Napoleón o redactando otro sobre el modelo), con el fin de eliminar las dificultades que la pluralidad y el fraccionamiento del Derecho causaban en la práctica jurídica. Propósito que suscitó la oposición conservadora, defensora de las características nacionales alemanas —lo representa bien la dialéctica SAVIGNY-THIBAUT-, aunque mucho de lo que se defendía eran los privilegios previamente adquiridos que una legislación como la francesa amenazaría. Como resultado, Alemania eludió el proceso codificador hasta principios del siglo XX, aunque se animó la conceptualización por la "Jurisprudencia de conceptos" como desarrollo del proyecto científico de SAVIGNY. 
lidó una iuspositividad cerrada sobre sí misma y sobre un dogma de "imperio legal" ajeno a pretensiones de corrección material y política. Todo el planteamiento se centró en torno a un ideal codificador de proyección atractivo-expansiva en todo el orbe jurídico-político y aliado a una TGD irrecusablemente descriptiva si no fuera porque su cerrazón objetivista se acompañaba de la renuncia, so pena de irracionalidad, a toda cuestión política, material, de corrección y coherencia valorativa. Por eso, aunque la teoría al describir no apoyaba ninguna ideología explícitamente, sí que limitó las posibilidades de conocimiento y corrección de la ley. Pues, si no se puede saber qué es una "buena" ley, porque todo lo que se diga que se sepa es falso, no cabe hablar de "malas leyes", por lo que cualquier teoría de la legislación constituye una fuente de permanente sospecha. La ley válida se perfecciona por condiciones procedimentales. Por eso, ni interesa ni cabe una teoría de la legislación, pues todo el terreno es ocupado por la teoría del derecho y el espacio colindante minado por ésta en su huída de la oscuridad metafísica.

Así las cosas, sólo cuando entra en crisis el modelo iuspositivo práctico y de conocimiento del Derecho ${ }^{19}$ y se institucionaliza el Estado social y el marco material neoconstitucional, la teoría y la técnica de la legislación renuevan sus fuerzas racionales inaugurándose lo que antes proponía como tercera etapa de la teoría de la legislación.

\section{EL RIVAL POSTMODERNO (O DEL SUMATORIO DE LOS VIEJOS Y NUEVOS PROBLEMAS DEL CÓDIGO): TIEMPO DE DESCODIFICACIÓN E IMPOSIBLE ACHIQUE DEL DESBORDAMIENTO DE FUENTES}

(11) La realidad material y el desarrollo sociopolítico demostraron que las necesidades, intereses y aspiraciones de la sociedad política superaban y daban al traste con el ideal codificador diseñado para homogeneizar el modelo de ordenación y protección estatal. De tal suerte que la transformación material del Estado de Derecho liberal en Estado social vuelve injustificables los criterios propietarios, excluyentes y centralistas, a la par que se produce un desbordamiento (cuantitativo y cualitativo) normativo como consecuencia del interés legislativo por atender a las múltiples expectativas vinculadas a distintos centros de interés.

En este contexto, y por la eficacia del binomio teoría/práctica, la práctica se antepone a la racionalización teórica imposibilitando la sistematización que trata de encauzarla; la praxis, así, se desboca, lo que conduce al espíritu científico del Código a un difícil vericueto: por su incapacidad para definir y cerrar sistémicamente el cuerpo de un Derecho que ya se ha desbordado sistemáticamente; por la transformación de los parámetros de racionalidad socialmente operativos; por su falta de recursos para alcanzar los objetivos de los nuevos modelos de Estado; y, además, por su tendencia a legitimar el voluntarismo legislativo como fuente de racionalidad elevada a su máxima expresión, la ciencia objetiva y predictiva.

19 Así, se puede decir que «la técnica legislativa surge de la necesidad de dar una respuesta práctica a la crisis, y la teoría de la legislación de la necesidad de encontrar una explicación teórica del fenómeno» (ATIENZA, 1997: 25). 
Al final parece que el proyecto racionalizador codificador — de un legislador embriagado del espíritu científico que organizaba todo el orden social a través de leyes y fórmulas mágicas y de una aplicación judicial verdadera articulada lógicamentemintió en lo fundamental. Porque respondería a un planteamiento político que, bajo las excusa de certeza, plenitud, simplicidad, abstracción, homogeneización normativa y universalización de las soluciones jurídicas ${ }^{20}$, no garantizaba la seguridad en la igualdad para el disfrute de los derechos. Porque fomentaba un nuevo clasismo alentado por el derecho de propiedad. Porque somete a la mujer al marido, que es quien se encarga de la actividad económica, negocios jurídicos, de representar a la esposa, de administrar y usufructuar los bienes de ésta y de decidir sobre su persona. Y porque instrumentó «la "amputación del cuerpo del derecho"..., la aniquilación efectiva de muchos sectores jurídicos a favor de uno sólo» (ÁlvVAREZ Alonso, 2003: 6).

(12) La consecuencia de esta caída racional es la huida de la codificación en una ida a un «proceso de consolidación y nacimiento de los micro-sistemas» (IRTI, 1992: 30) que expresan las múltiples racionalidades operativas en una dinámica cambiante del sistema político-social. Con ello se trata de dar respuesta a una comprensión actualizada del concepto de individualidad, interés y Estado que opone la codificación a la proliferación real de la legislación especial ${ }^{21}$.

Lo que la actual «edad de la descodificación» (IRTI) descubre es la falta de racionalidad nomológica codificadora: su concepción de la ley es rebasada en todos sus aspectos y, ahora, lo que proclama el principio de división de poderes es el control judicial de la legislación, el condicionamiento sustantivo de la validez ${ }^{22}$, la ampliación de la potestad legislativa del ejecutivo, la disgregación de fuentes internas y externas que actúan sobre el Derecho nacional, etc.

Así las cosas, la crítica postmoderna objeta a la codificación moderna y liberal ${ }^{23}$ : 1) el permanente cambio de la estructura social estatal y extra-estatal —alimentados incesantemente por la economía y la tecnología - que mina su relación con el ámbito jurídico y «la ilusión social de la integración del desorden en el orden» (CARRIONWARM); 2) el debilitamiento jurídico de las fronteras racionales; 3 ) el enfrentamiento de la codificación formal a la codificación constitucional material y de principios. Por todo ello, destaca el crítico, ha llegado ya el momento de dar fe pública de la caída del modelo codificador, pues la dinámica y cambiante realidad político-social ya no se deja someter a quijotescas empresas de enclaustramiento en las rígidas fórmulas generales codificadoras ajenas a las posibilidades de ajusticiamiento constitucional y judicial.

Pero si el nuevo proyecto en el que está embarcado el Derecho - la vinculación Estado-sociedad, creciente intervencionismo del Estado y de su función económiconormadora, alteración del sistema de fuentes, la impronta neoconstitucional y el aumento de la discreción valorativa que imprime...- rebasa las posibilidades de las

20 En similar sentido, VARGA, 1978: 30 y ss.

21 «Las normas especiales, si por un lado constituyen el factor dinámico del ordenamiento, por otro parecen amenazar o comprometer la unidad..., infringen los esquemas de la generalidad, introducen criterios fluidos e inestables. Cuanto más penetran y se extienden, tanto más parece perdida la unidad» (IRTI, 1992: 59).

${ }^{22} \mathrm{Al}$ respecto, Ferrajoli, 2004: 33-34; tmb., idem, 2001: 43 y ss.

23 Complementariamente, Grossi, 2003: 88-90. 
leyes codificadas, únicas, claras y generales, lo peor aún llega al percatarnos de que una solución irreflexiva y proclive a la proliferación millonaria de leyes incomprensibles, carentes de generalidad y abstracción, de orígenes distintos al legislador tradicional, que conducen a confundir los tres poderes, al judicialismo, el ejecutivismo, etc., socava todas las condiciones que deberían limitar y orientar la legislación. Pues, si el descontrol del legislador es un riesgo efectivo para los derechos individuales, el problema no se resuelve en el Estado social sobredimensionando la legislación particular, el ajusticiamiento discrecional, el proceso paralelo de la contractualización del Estado ${ }^{24}$, las regulaciones acordadas que eviten el conflicto (se evidencia en el marco laboral) y las reglamentaciones administrativas ajustadas a criterios, entre tecnocráticos y discrecionales, carentes de un sistema de organización racional ${ }^{25}$.

\section{NEOCODIFICACIÓN Y ARGUMENTACIÓN (O DE LA IMPOSIBLE DESCODIFICACIÓN POSTCODIFICADORA): ¿ES NECESARIA Y POSIBLE LA NEOCODIFICACIÓN?}

(13) El esfuerzo legislativo estatal de los 50 y ss. por adaptarse e intervenir en una sociedad crecientemente plural y segmentada por múltiples focos de interés se une al fenómeno de la globalización económica a partir de los 70 y ss. Ahora ya no basta con garantizar el orden social, sino que las exigencias de una soberanía popular materializada exigen atender al orden del desorden de las expectativas e intereses en conflicto. Por eso se ha multiplicado en volumen y tipología la legislación... hasta el desbordamiento, por satisfacer, aunque sea de forma sucesivamente contradictoria, las demandas del consumidor/votante satisfecho.

En este contexto, repensar la codificación, racional, sistémica, unitaria, estable, general, parlamentaria, etc., es problemático en sentido fundamentador, porque la fundamentación está más del lado del discurso, el consenso, la transacción y la pluralidad que tanto escasean en el programa codificador. Pero además, parece ya imposible en el nivel práctico.

$\mathrm{Y}$ es que lo que hoy preocupa y se cuestiona ya no es tanto el acto de voluntad soberano que antaño centrara la discusión doctrinal, sino más bien cómo definir y remodelar los aspectos centrales de la simplificación, racionalización y justificación prometidas por la concepción político-liberal para encauzarlos a la soberanía socializada del Derecho. En particular, la crisis codificadora deja al desnudo la definición del "iura novit curia": qué pretende, qué abarca, qué límites tiene; cómo se garantiza

${ }^{24} \mathrm{Al}$ respecto, IRTI, 1992: 30-33.

25 Así: «(l)a multiplicación de las leyes jurídicas... hace que el ciudadano que, para poder observarlas debería conocerlas, ya no tiene la posibilidad de conocerlas. La publicación de éstas, como condición de su imperatividad, ha cambiado de carácter, de ser una presunción se ha convertido en una ficción. El hombre de la calle está desorientado en el fango de la ley... Cuanto más crece el número de leyes jurídicas más disminuye la posibilidad de que sean formuladas de forma adecuada y ponderada... La función legislativa desborda ahora del álveo en el que debería contenerse según los principios constitucionales... Por otra parte, la creciente velocidad de la vida social repercute necesariamente sobre la vida de la ley... las leyes ya no consiguen llegar a viejas» (CARNELUTTI, 1953b: 280, tmb. pp. 276 y ss., en particular p. 290, idem, $1953 \mathrm{a}, 66$ y ss., idem, 1953c: 153 y ss.). 
la razonabilidad del principio «la ignorancia del Derecho no excusa de su cumplimiento»; qué aporta realmente la exigencia de publicidad de las leyes, para quién es público e inteligible el mare mágnum legislativo y sus múltiples interpretaciones constitucionales; cuáles son los criterios de interpretación; cómo se garantiza la coherencia y la plenitud sistémica en caso de antinomias intra e internormativas y de no regulación específica; de qué nos hace estar seguros la seguridad jurídica, etc.

(14) Al respecto, partiré del siguiente planteamiento: la comunicación que da existencia al subsistema social del sistema jurídico responde a la traducción de los distintos factores de controversia al sistema jurídico significativo y a la pretensión de reducción de complejidad a la que se orienta el Derecho, por lo que existiría una especie de "lógica interna" en la autoordenación y reordenación permanente de ese Derecho. Lo que importa de los sistemas de comunicación es que funcionen, que reduzcan la complejidad significativa y de expectativas en la ordenación de relaciones. Y el Derecho funciona al ser capaz de clasificar el Derecho frente al no-Derecho y al otorgar significación jurídica a ciertas acciones de comunicación, al margen del sistema moral, político, religioso, etc.

Ahora bien, dicho esto, hay que reconocer que la comunicación que da sentido, crea y sostiene al sistema jurídico está muy relacionada con el sistema político y que, internamente, es constantemente segmentada por la interpretación teórica de la praxis jurídica, política y social. Así, lo que el sistema de Derecho comunica en orden a reducir la complejidad de la praxis se redefine permanentemente por comprensiones teóricas que están íntimamente vinculadas a, y afectadas por, las tensiones, condiciones, interpretaciones y comunicaciones de otros subsistemas sociales (moral, religioso, económico, etc.) y en una forma destacada, y no sólo espontánea, por el sistema político aunque sea conformándose a las claves de éste.

Como actualmente la ley no funciona como se pretendía, ni se entiende en su dimensión estrictamente voluntarista, sino que se adorna de una red de consideraciones políticas y de fundamentación, resulta que la reducción de complejidad político-social que opera el Derecho cede en favor de una concepción sustantiva. Dicho en términos genealógicos (FOUCAULT), la ley fue construida a favor de una concepción del poder centralizado que reconducía el nudo de conflictos sociales y de poder al único conflicto de la soberanía de un Derecho unificado, en su máxima expresión codificado. Pero esa genealogía de la centralidad es hoy presionada por el tejido reticular que conforma la sociedad hasta diluirse la unicidad en la complejidad. El Derecho ha respondido dispersándose, para responder a una arqueología de la sociedad en conflicto segmentada por intereses y poderes varios, buscando una fundamentación teórica político-valorativa que encauce el desarrollo del discurso práctico del Derecho.

Esto significa que el Derecho anda tras criterios racionales que superan el marco de codificación formal jurídico/no-jurídico para redefinirlo. El esfuerzo de redefinición jurídica surge cuando las consideraciones fundamentadoras y político-sociológicas rebasan el marco codificador de simplificación jurídica codificador. La nueva realidad precisa para reducir su complejidad y ganar en racionalización jurídica una teoría legislativa que habilite una adecuada técnica de juridificación y resuelva la obstrucción codificadora. Para ello hay que conectar los criterios de fundamentación del orden 
político, la democracia y el Estado de Derecho, con la articulación positiva de los derechos y la seguridad jurídica y con los recursos constitucionales, legislativos, ejecutivos y judiciales.

(15) El papel de la codificación en este proceso depende de su intimación consustancial con la Constitución, de su función constitucional ${ }^{26}$. Por eso, lo que la actualidad exige es segmentar el proyecto codificador conforme al modelo neoconstitucional. Esto es, superada la consideración programática de las Constituciones materiales — para la que «el Código encarnó la auténtica Constitución del Estado burgués» (GROSSI, 2003: 90) - por su definición normativa y legislativamente vinculante ${ }^{27}$, ampliado el elenco de los derechos protegidos constitucionalmente a los derechos sociales y sometido el legislador al control constitucional material de su actuación, la articulación y funcionalización de la codificación debe reorientarse al servicio de las nuevas exigencias constitucionale ${ }^{28}$ y que refuerzan la definición liberal del Estado democrático de Derecho ${ }^{29}$ a garantizarse las condiciones de producción y la accesibilidad a las normas y la seguridad jurídica frente a los picos que caracterizan la crisis de la legislación (hiperregulación, mala calidad de las leyes, dispersión, alteración del sistema de fuentes, discrecionalidad principialista) ${ }^{30}$. En concreto, la actualización neoconstitucional de la codificación estaría al servicio de los principios de legalidad, separación de poderes, interdicción de la arbitrariedad y seguridad jurídica, pero en un marco socialdemocrático y de interconexión Estado-sociedad que exige una fundamentación discursiva orientada a la dinámica cambiante del consenso.

(16) Por ello importa siquiera recordar el vínculo seguridad jurídica-codificación.

La seguridad jurídica no adquiere su condición de valor jurídico fundamental por la trascendencia que le otorgan "los" iuspositivistas, sino que más bien, en el mismo sentido pero en dirección contraria, se vincula a los presupuestos de la definición política liberal del Estado de Derecho y se radicaliza en sus exigencias con la conversión de éste en Estado social. Si el Derecho es hecho por el pueblo y para el pueblo para constituir y preservar sus derechos, libertades y garantías, entonces el Derecho debe poder ser conocido y sus aplicaciones prácticas deben ser razonablemente previsibles. Y esto al menos exige una racionalización y una sistematización coherente, clara, inteligible, liberada de contradicciones irresolubles, con una técnica legislativa adecuada y pragmáticamente conectada con la realidad a la que se refiere.

Por eso una codificación adecuada coadyuvaría de forma esencial a la consecución de la seguridad jurídica. Por eso, nuestro TC en distintas ocasiones ha destacado

26 Véase TARello, 1976: 22 y ss.; complementariamente, DE los Mozos, 2001: 3.

27 Por eso, «difícilmente se podrá repetir que autorictas non veritas facit legem» (LA TORRE, 1993: 73). Pues, aunque la ley sigue siendo expresión de una autoridad, ésta ya no queda sólo abandonada a la voluntad, sino que la autoridad legislativa es «una autoridad sometida a la verdad, siquiera sea una peculiar "verdad" normativa» (PRIETO SANCHÍS, 1999: 35) dado el efecto rematerializador y vinculante del constitucionalismo contemporáneo.

28 Porque «la ley es definida a través, y subordinada a, criterios sustantivos cuya formulación explícita es sancionada por la Constitución» (LA TORRE, 1994: 652).

29 Al respecto, CAZORLA PRIETO, 1999: 50 y ss.

30 Veánse, p. ej., informes de 1991 y 1992 del Consejo de Estado francés; complementariamente, BRAIBANT, 1999: 91 y ss. 
la interconexión entre ambas ${ }^{31}$. Y, por eso, el argumento de la seguridad jurídica, como valor esencial de los escenarios constitucional y neoconstitucional, reclama un nuevo proyecto codificador que no puede ser ya el decimonónico, pero que debe garantizar una posibilidad de conocimiento y control del Derecho que garantice la previsibilidad de la praxis jurídica, facilitando que el Derecho reduzca la complejidad en favor de la protección de los derechos, libertades y garantías liberales.

(17) Pero que la codificación sea necesaria y justificable no aclara cómo debería ser su articulación posible en el marco teórico y práctico del Estado de Derecho neoconstitucional.

Pues bien, la propuesta es reconstruir una codificación atenta a la realidad dinámica del Derecho y a una comprensión dispersa del mismo que se posibilite y además se justifique por atender a sus múltiples centros constitutivos de significación.

Esto obliga a alterar el ideal ilustrado manteniendo su aspiración racionalizadora y sistematizadora pero renunciando a una codificación cerrada y definitiva, tal como exige una fundamentación discursiva y el criterio "procesal" 32 de interpretación constitucional, el más acorde con la justificación racional de la Constitución y con las exigencias de la legislación al fomentar la apertura y representatividad de los cauces democráticos. En concreto, es necesario:

En primer lugar, que la codificación permanezca abierta enfrentándose a un permanente proceso de reelaboración a (del) Derecho constante conformado a la realidad político social (así se está intentando, enfrentándose a las dificultades que van apareciendo, en EE.UU., en Francia, en parte en Alemania, y también en Inglaterra, p. ej., con las Consolidation Acts).

Segundo, que se atienda a la teoría de la legislación para centrar la definición del legislador democrático y adecuar el proceso de elaboración de las leyes a las exigencias de participación y satisfacción de expectativas del Estado social de Derecho para hacerlo realidad.

En tercer lugar, que se redefina la función judicial ahora que sabemos que el silogismo es imposible y también que la estricta reconducción de la jurisdicción a la ley fortalece la idea del soberano que decide unilateralmente cerrando un sistema lógico del que se cree poder obtener consecuencias ex principiis derivationes ${ }^{33}$. Por eso, volver

31 P. ej., cuando define (STC 27/1981, 20 de julio) la seguridad jurídica como suma de todas las condiciones del art. 9.3 CE destacando la relación de la seguridad jurídica con la certeza, jerarquía y publicidad normativa, ideales propios el proyecto codificador. Posteriormente, el TC rehúsa incluir ciertas materias en la Ley de Presupuestos Generales del Estado «por afectar al principio de seguridad jurídica debido a la incertidumbre que una regulación de este tipo originaría» (STC 76/1992, 14 de mayo; fdto. jdco. $4 .^{\circ}$ ); este vínculo entre seguridad jurídica y certidumbe reenvía a la codificación, pues ésta «tanto en el plano ideológico o material como en el formal, con todas las técnicas jurídicas acuñadas a tal efecto, pregona y busca sin cesar la certidumbre en las situaciones y relaciones jurídicas» (CAZORLA PRIETO, 1999: 57). A esto debe añadirse la función de interdicción de arbitrariedad que puede cumplir el proyecto codificador, algo que nuestro TC reconoce al objetar las afirmaciones antinómicas en el ordenamiento.

32 Frente a las interpretaciones "originalista", fiel a la intención del autor de la Constitución, "interpretacionista” o de adhesión a los valores culturales de la sociedad en cuestión y deconstructiva (atiéndase a BuRT, 1995: 1-3).

33 Pues hoy «(n)i todo lo que hace el juez es fácilmente reductible a la noción abstracta de sentencia judicial, ni todo lo que hace el legislador es fácilmente reductible a la noción abstracta de norma general y de duración indefinida con la que se quiere identificar la ley» (RUBIO LLORENTE, 1990: 105). 
a codificar exige prestar atención al valor de la iuris prudentia, como instrumento práctico de creación del Derecho, de consolidación de los criterios interpretativos y argumentativos y de vigorización de la seguridad jurídica. Tal planteamiento fortalece la idea, bien conocida en el ámbito del common Law ${ }^{34}$, de que el Derecho se integra dialécticamente en un proceso que se solventa en un sentido importante en el ámbito judicial constituyendo un sistema siempre imperfecto y abierto ${ }^{35}$ — pues la aplicación de las normas es un tramo más de constitución y regulación normativa que contribuye a fijar su pragmática operativa dinámicamente-. A estos efectos, una integración crítica de las líneas interpretativas jurisprudenciales en un cuerpo legal codificado tanto serviría para dar sentido práctico a la ley, cuanto exigiría y contribuiría a una codificación dinámica y a tiempo real —aunque sea ultimada y ratificada por el legislador democrático- ${ }^{36}$.

$\mathrm{Y}$, además, cuarto, la neocodificación dinámica reclama fomentar la participación efectiva de los representantes de los grupos de interés público y privado afectados por las normas y de las diversas instituciones que segmentan y encauzan la comunicación jurídica en los distintos ámbitos materiales, para garantizar la viabilidad discursiva, otorgando verdadero sentido material al modelo neoconstitucional y contribuyéndose, así, a la actualización pragmática de los compendios normativos que explicitan y racionalizan la voluntad legislativa.

(18) Lo difícil es "realizar" este reclamo complejo de racionalización y sistematización legislativa a tiempo constante y que desplaza el centro legicéntrico de la codificación liberal al multicentrum de la significación jurídica actual.

Sin embargo, la dificultad no es incapacitante, y así lo demuestran algunos de los esfuerzos neocodificadores actuales y que tratan de responder a la crisis de la vieja codificación. En concreto, me interesaré por el modelo operativo en EE.UU., también por el nuevo armazón codificador implantado en el imperio codificador francés ${ }^{37}$; luego los pondré en contraste con el planteamiento español.

34 Complementariamente, LEE, 1990: 84 y ss.

35 Al respecto, ZAGREBELSKY, 2003: 26 y ss.

36 En este sentido hay que mencionar no sólo el esfuerzo estadounidense, sino la reforma del BGB alemán que impulsa la Ley de Modernización del Derecho de Obligaciones (1-1-2002) al introducir una nueva codificación del libro segundo sobre el Derecho de obligaciones (una de las partes más dinámicas del ordenamiento jurídico). Conforme a la misma, y renunciando a una mera traspolación de la legislación especial al Código, se revisa el complejo sistema del derecho de incumplimiento, se codifican figuras jurisprudenciales (la culpa in contrabendo, la lesión positiva de la pretensión contractual o la revisión del contrato por alteración de las bases de negociación), se rearticula la compraventa y se introducen compraventas especiales, se modernizan los contratos de préstamo y obra y la prescripción extintiva, etc. También se integra el Derecho de consumo contractual, esto es, la legislación de protección del consumidor (como la venta a domicilio, los contratos a distancia, ...), lo que hace que desaparezcan las numerosas leyes especiales de consumidores, se armonizan Directivas de consumidores, se incorporan armónicamente tres leyes especiales de consumo y sólo se deja fuera una (la Ley de responsabilidad por productos defectuosos). Y, además, la nueva codificación tiene en cuenta los Principios Unidroit (Instituto Internacional para la Unificación del Derecho Privado) y la Convención de Viena de 1980. (Complementariamente sobre la reforma compleja de neocodificación alemana, Albiez DOHRMAnN, 2003: 138 y ss.; CAÑIZARES LASO, 2003: 409 y ss.).

37 Desatiendo, así, más por cuestión de espacio que por falta de interés, el propósito codificador vigente en UK desde que en 1965 las Proposal for English and Scottish Law Commissions (Cmnd. 2573) establecieran que «el Derecho inglés debería ser capaz de presentarse de un modo accesible, inteligible y acorde con las necesidades modernas»; y para ello se requería con urgencia desbrozar y “consolidar” — «sancionar en una 
(19) En EE.UU. se impuso el dominio del common Law frente al desarrollo codificador, al que se consideró característicamente inflexible, desatento a la justicia del caso concreto y fuente de una incontrolada discrecionalidad legislativa y judicial. Pero esta renuncia codificadora no libró a la administración de justicia estadounidense de una fuerte insatisfacción. Por eso BENTHAM se ofrece (1811) al presidente Madison para emprender la codificación del Derecho norteamericano, propuesta que el presidente rechaza ${ }^{38}$. A partir de ahí en EE.UU. se fortalece la idea de que es necesario ordenar y racionalizar el material jurídico que prolifera amparado por el common Law.

Es esto precisamente lo que sostiene el informe de 1920 del Comité que establece una organización permanente para la mejora del Derecho y que propone la creación del "American Law Institute" ${ }^{39}$. Éste inicia una línea positivizadora y racionalizadora que unida a esporádicos esfuerzos codificadores y a la consolidación de ciertos Códigos y de una Constitución (1787) se distancia de la ortodoxia del common Law sajón, mas confiado en la tradición y las costumbres.

En su informe el Comité expone los principales defectos del Derecho en Norteamérica, justifica y explicita la naturaleza sistematizadora, no estrictamente codificadora en el sentido europeo, de los Restatements of the Law, y el vínculo de sus propósitos con la legislación.

Los Restatements sistematizan leyes, jurisprudencia y doctrina racionalizándolas y ordenándolas para ofrecer una visión «analítica, crítica y constructiva del Derecho». - Por lo que siendo «su intención establecer el derecho en términos autoritativos y comprensivos... se le dé el nombre que se quiera, es una especie de codificación» (YNTEMA)—. Su finalidad básica es solventar la incertidumbre y la complejidad «que

ley todo el Derecho, incluido el casuístico, en relación con un tópico» (CuRZON, 1995: 288)— el Derecho establecido. Para ello se establecieron unas Comisiones que debían recoger y revisar todo el Derecho que les afectaba respectivamente (en 1967 se identificaron 17 materias) animando una reforma orientada a un desarrollo sistemático armonioso del material existente. Inicialmente el interés se centró en el marco contractual, pero en su Segundo Programa, de 1968, la Comisión del Derecho propuso, con los ojos puestos en una codificación, un examen comprehensivo del Derecho criminal. En 1981 se definió el equipo codificador que debía formular en un modo apropiado al Código los principios generales que deberían regir la responsabilidad penal, una terminología estándar y las reglas que debían regir su interpretación. Finalmente el Código Criminal se publica en 1985. Luego, en un Informe en 1990, la Comisión del Derecho sugirió que el trabajo de la codificación debía continuar «a través de una serie de informes que recomendarían la reforma o la reinterpretación sistematizadora de las áreas de los delitos específicos... junto con la reformulación de los principios generales relevantes».

38 Aunque hay que reconocer que en EE.UU, más que en Inglaterra, la preocupación por la incertidumbre normativa y la inseguridad que generaba data de antiguo, convirtiéndose el proyecto codificador en fuente de permanente controversia, al menos, desde que en 1634 se iniciara el movimiento codificador en Massachusetts, donde designó una Comisión de codificación, de la que forma parte Story que contempla la desordenada realidad y el "laberinto misterioso" (SAMPSON) del common Law como una «calamidad espantosa que amenaza con enterrar vivos a los juristas americanos no en las catacumbas sino en los laberintos del Derecho»; también fracasa este intento. A partir de ahí el interés por codificar y racionalizar el Derecho es zigzagueante pero permanente, fortaleciéndose en el siglo XIX (más detalladamente, TUNC \& TUNC, 1957: 466). Así, FIELDS trataría de sancionar un Código Civil para Nueva York centrado en la idea de fórmulas sistemáticas y accesibles, expulsión de anacronismos y adaptación a las condiciones de la época. Fracasó en Nueva York (quizá por el contexto colonial y vinculado a la tradición inglesa), aunque su Codigo Civil fue acogido en Dakota (1865), California (1872), Idaho (1887) y Montana (1895). También en Louisiana se sancionó un Código Civil en 1808, reformado en 1819 y 1825 que, a pesar de los embates del common Law, se confirma actualmente como un «sistema jurídico sui generis» (DAINOW, 1954: 32).

39 American Law Institute Proceedings 1-28 (1923). 
causan la inutilidad del litigio, obstaculizan el recurso a los tribunales para garantizar derechos justos, hacen imposible advertir e informar a las personas de sus derechos, y cuando el litigio se ha iniciado, generan retraso y gastos». Para ello, y elaborados por Asociaciones de especialistas supervisados por el American Law Institute (ALI) (creado en 1923 e integrada por jueces, profesores y profesionales del Derecho), los Restatements definen un sistema organizado «sobre los principios fundamentales del common Law, otorgan precisión al uso de los términos legales y hacen el derecho más uniforme en el territorio». El $A L I$ estableció ${ }^{40}$ que esa síntesis de Derecho adoptaría la forma de reglas estatales y que, aunque no tienen fuerza de ley, son fuente autoritativa para muchos tribunales al basarse en la opinión experta de los profesionales del Derecho y resultar «de un cuidadoso análisis de la materia y del examen y discusión de los casos, frecuentemente numerosos y en ocasiones en conflicto, aunque no sean fuente primaria de Derecho ${ }^{41} \gg$ (Restatement of Contracts, xi-xii, 1932) .

En síntesis, los Restatements son esencialmente codificaciones del common Law convertido en doctrinas que se desarrollan gradualmente en el tiempo propiciados por el principio de stare decidis ${ }^{42}$. Su objetivo, así, es destilar la «letra negra del Derecho» de los casos para indicar una tendencia establecida en el common Law reconduciéndolo a una serie de principios o reglas y, ocasionalmente, recomendar cómo debería ser una regla de Derecho. Formalmente, los Restatements se organizan en capítulos, títulos y secciones, y cada sección contiene una regla de Derecho concisamente establecida, así como los comentarios para clarificarla, ejemplos hipotéticos, la explicación de su propósito y la previsión de sus posibles excepciones.

Junto a los Restatements, también es representativo del nuevo esfuerzo codificador norteamericano actual, de un lado, la elaboración del Uniform Commercial Code —que pretende materializar la codificación del Derecho comercial iniciada en los 40 y ss. y encabezada por Llewellyn-; especie de ley que todos Estados asumen, aunque complementándola conforme a sus particularidades, y que los abogados utilizan como primera referencia. Y, de otro lado, los proyectos en marcha del U.S. Code (USC), referido a la leyes, y el Code of Federal Regulations (CFR) que codifica las normas reglamentarias.

El U.S. Code es más una compilación que un Código en sentido estricto; es «una nueva presentación oficial (the official restatement) en forma práctica de las leyes generales y permanentes de los Estados Unidos» (Prefacio). Su pretensión es sistematizar y ordenar por materias para racionalizar el sistema de legalidad, favoreciendo la fácil identificación de las leyes y eliminando las ambigüedades, contradicciones y otras

${ }^{40}$ Complementariamente, HART JR., SACKS, 1994: 726 y ss.

${ }^{41}$ Así, los Restatements constituyen la fuente secundaria más autorizada del Derecho norteamericano —citados más de 161.000 veces por los tribunales hasta mediados del 2005 (Appendix to the Director's Report del $A L I)$.

${ }_{42}$ Las decisiones previas deben reconocerse como precedente por el órgano judicial abarcando la stare decidis vertical: la decisión de un órgano superior constituye un precedente que el tribunal inferior no puede desatender; y la stare decidis horizontal: el tribunal debe seguir sus propios precedentes (excepto si posee una razón fuerte para no hacerlo, en cuyo caso seguirá los principios provenientes de tribunales laterales y de otros inferiores) y los de los órganos jurisdiccionales que operan en su "circuito", de modo que los precedentes de un tribunal de apelaciones sólo pueden desatenderse "en banc", en una sesión de los jueces de apelación del circuito, o por el TS de los EE.UU. 
imperfecciones. Pero sin obstaculizar su innovación, por eso se actualiza periódicamente (cada seis años, con suplementos anuales) ${ }^{43}$.

Incialmente el Code tenía fuerza presuntiva respecto de la existencia de las leyes: en caso de desacuerdo sobre los textos que regían una materia debía acudirse a los Statutes at Large (edcs. 1934, 1940 y 1946). Pero, a partir de 1947 se inaugura la técnica de que los distintos títulos, sucesivamente y tras su revisión, los apruebe el Congreso. Cuando aparece una ley se relaciona con el Código para incluirla en él si no lo modifica en alguna de sus partes.

Por su parte, el Code of Federal Regulations aglutina y sistematiza los desarrollos reglamentarios integrando las reglas generales y permanentes publicadas en el Registro Federal por los departamentos del gobierno y las agencias del Gobierno Federal. Está dividido en 50 títulos que representan amplias áreas de la regulación federal y, por su mayor volumen, se actualiza trimestralmente por títulos completos y una vez al año estructuralmente.

Estos apuntes generales muestran que incluso EE.UU. considera ya probada la necesidad codificadora, aunque conformada a las necesidades pragmáticas del Derecho efectivamente operativo. Y que por eso se han iniciado distintas vías que no sólo dan cuenta de la posibilidad codificadora en el moderno Estado de Derecho, sino también del esfuerzo por lograr una racionalización del Derecho concebido desde una perspectiva dinámica y policéntrica.

(20) Pero también se desarrolla una nueva empresa codificadora en Francia, cuna de la codificación legicéntrica, una vez se reconocen las incapacidades del Código decimonónico.

Aunque en Francia la codificación napoleónica ha demostrado su resistencia, lo cierto es que ha envejecido ${ }^{44}$. Por eso se está intentando un sistema codificado de nuevo cuño que ni imita la codificación napoleónica, las circunstancias políticas, sociales y jurídicas tampoco lo permiten, ni pretende una codificación innovadora (como la de Quebec o el Códido Civil alemán). Más bien introduce una nueva técnica de «codificación a Derecho constante» para garantizar la accesibilidad e inteligibilidad de la ley y proteger la seguridad jurídica (Consejo Constitucional).

La codificación francesa a Derecho constante la realizan drafstmen gubernamentales que revisan las dispares fuentes de legalidad para darles forma coherente. Así, no se trata de una habilitación al gobierno para que modifique las leyes a su antojo, más bien se le faculta a perseguir los objetivos de: $i$ ) precisar los términos legales para hacerlos más comprensible pero respetando el principio de legalidad; ii) mejorar la redacción de los textos y la adaptación terminológica; iii) eliminar las disposiciones implícitamente derogadas; $i v$ ) distribuir los textos conforme a su naturaleza legal o reglamentaria; v) armonizar el Estado de Derecho.

${ }^{43}$ Desde que comenzó a publicarse en 1926 muchos títulos del Código ya han sido promulgados como Derecho positivo, conforme a una formación y mantenimiento que depende de un Revisor of Statutes adscrito a la Office of the Law Revision Counsel of the House of Representatives, que es nombrado por el Congreso.

${ }^{44}$ Entre 1989 y 1997 ven la luz 5 Códigos que derogaron más de 400 leyes especiales. Y antes del 2010 deben entrar en vigor 60 Códigos que deben solucionar la inflación normativa y la inseguridad jurídica. 
Esta labor se impulsa a través de Comisiones de Codificación y por una Comisión Superior de Codificación básicamente encargada de la codificación de lege lata, señalando los preceptos implícitamente derogados, las contradicciones, advirtiendo modificaciones formales y dando una ordenación sistémica desde la perspectiva de Derecho constante, que procura las innovaciones y puesta al día y la integración en los valores constitucionales y en el conjunto del sistema jurídico.

Un aspecto destacado de la nueva codificación francesa es que desde 1989 estos Códigos pasan al Parlamento, que los estudia, articula y da valor de ley con efectos derogatorios sobre lo no incorporado en ellos; «(e)llo permite descargar al Derecho de la complejidad de las acumulaciones constantes e inciertas y da a los Códigos un valor normativo pleno y superior, que mediante cortes sistemáticos y sucesivos aclaran y despejan el panorama normativo» (GARCÍA DE ENTERRÍA, 1999: 65).

Además, la ambición del nuevo programa francés condujo a que, a fines de 1999, una ley apoderara al gobierno, dada la ampliación práctica de su labor legislativa y que ésta se entendió justificada, para actuar a través de Ordenanzas no ratificadas por el Parlamento para «proceder... a la adopción de ciertos Códigos», lo que convierte al gobierno en agente fundamental de la labor codificadora. Antes de 1999 se trataba de una codificación por decreto, administrativa, que no podía repeler o reemplazar las previsiones legales iniciales, pero esto generó un orden paralelo, el de las provisiones regulatorias novedosas y el de las leyes, suscitando una gran incertidumbre que debilitó el proceso codificador. Para resolver el problema aparece la ley de habilitación de 1999, conforme a la que las secciones de legislación ya codificadas mantienen su naturaleza legislativa, por lo que pueden derogar leyes previas. Aunque «sólo deberían darse las modificaciones estrictamente necesarias para la coherencia del Derecho» (FAUVARQue-Cosson).

Ahora bien, esta habilitación, aunque por cierto muy efectiva a la vista del número de Códigos adoptados, planteó y plantea diversos problemas.

De un lado, se cuestionó la constitucionalidad de la misma al aparentar una usurpación de los poderes parlamentarios legislativos. Sin embargo, el dictamen del Consejo Constitucional ratificó su constitucionalidad ${ }^{45}$.

De otro lado, como la habilitación al ejecutivo no le faculta para suplantar al legislador parlamentario, se objeta que con ella se muestra y a la par se encubre la necesidad de que el legislativo haga un Derecho general adecuado, estableciendo nociones, clasificaciones, conceptos, etc. (ATTIAS). Si bien, y a pesar de lo adecuado de la objeción, hay que reconocer que, más que enfrentarse al esfuerzo neocodificador, destaca el desinterés o incapacidad legislativos por establecer una estructura jurídica que posibilite la neocodificación a Derecho constante.

${ }^{45}$ Apelando al art. 38 de la CF que habilita al gobierno a actuar por ordenanzas si media una ley aprobada en el Parlamento; como esa ley habilitadora existe y sólo permite al gobierno cambios orientados a armonizar el Derecho preexistente, cae dentro del art. 38 CF. Pero, a pesar de todo, se insiste en los problemas relacionados con la jerarquía normativa y la "necesidad" de deslegalización (déclassement) reglamentaria (a fin de lograr una regulación codificadora) de materias previamente reguladas por la ley (véase RoIG, 2003: 73 y ss.) - proceso amparado por el art. 34 CF que diferencia materias legales y reglamentarias y que interpreta el Consejo Constitucional afirmando el carácter reglamentario o no de la materia para, a partir de ahí, proceder en su caso a deslegalizarla. 
Además, y a pesar de lo plausible de este proyecto neocodificador, habría que: i) determinar la trascendencia teórica y práctica de las resoluciones judiciales para concretar el Derecho; ii) depurar los órganos codificadores para que tengan un conocimiento y unas habilidades constructivas apropiadas a la empresa que se les encomienda; iii) determinar el tratamiento adecuado de aquellos ámbitos jurídicos que carecen de código pero que exigen certeza y un acceso sencillo, etc.

(21) Creo que basta lo expuesto para afirmar que, a pesar de los problemas que enfrentan los nuevos proyectos de codificación como el estadounidense o el francés, ambos demuestran un interés teórico y práctico por enfrentarse, con los permanentes reajustes pertinentes, a una misma realidad jurídica desordenada, hiperabundante y sometida a una dinámica difícilmente controlable.

(22) Pero ¿qué pasa y qué se intenta en España? Pues bien, resulta que el legislador español parece sentirse más atraído que preocupado por esa realidad legislativa desbocada y desordenada, hasta el punto de "renegar" de un verdadero esfuerzo neocodificador ${ }^{46}$. Y digo esto porque aunque es verdad que España y Francia son los dos países que poseen una Comisión de Codificación — los demás actúan a través de comisiones especiales-, y aunque también es cierto que la española tiene un siglo más de antigüedad que la francesa, el RD 160/1997 que aprueba los nuevos estatutos de la Comisión Codificadora española, con pesimista resignación, da por concluida la codificación y, aparentando desconocer más Código que el decimonónico, se entrega a la realidad de las leyes especiales ${ }^{47}$, aun a costa de la dispersión y la oscuridad.

Considera la Comisión Codificadora española que la codificación es ya imposible y, así, declara la era "postcodificadora" entendida como "descodificación". Esto, unido a la supresión de la exigencia impuesta a fines de los 50 y ss. de que la nueva normación se acompañara de las "tablas de vigencias" ${ }^{48}$, reafirma la idea de que el legisla-

46 Enfrentándose así a los esfuerzos recodificadores y neocodificadores que se han desarrollado en los últimos 65 años —Código Civil italiano (1942); Código portugués (1966); Código Boliviano (1975); codificación peruana (1984), paraquaya (1986); Código de Quebec (1994); Código Holandés (1992); neocodificación francesa y estadounidense; reforma del Código Civil Alemán; codificación de Bolivia, Perú, Puerto Rico, Argentina, Brasil, etc.

47 «(N)uestra sociedad se muestra ya muy distante de aquella época en la que triunfó el ideal codificador. Nos encontramos en plena era de la postcodificación, o mejor, de la descodificación... los códigos han perdido su posición central y privilegiada en los sistemas jurídicos. En su lugar, las leyes especiales, por un lado, como normas necesarias de una sociedad en constante mutación y el texto constitucional por otro, como fundamento de los valores de un sistema político, han cambiado el sentido de la técnica legislativa» (Preámbulo RD 160/1997).

48 «Pauta de reflexión y racionalidad» (GARCÍA DE ENTERRÍA) que exigía que cada nueva disposición fuese acompañada de una relación de las disposiciones sobre la misma materia existentes y una declaración expresa de aquellas que quedarían total o parcialmente derogadas.

De haberse seguido escrupulosamente el imperativo de las tablas de vigencias que establecía la Ley de Procedimiento Administrativo de 1958 (art. 128.3), cosa que no ocurrió excepto respecto de los "textos refundidos", se habrían generado codificaciones parciales por materias que habrían actuado contra la incertidumbre. Sin embargo, el art. 24 de la Ley de Gobierno de 27 de noviembre de 1997, en vez de reforzar la exigencia, la elimina: «(q)ueda así confesado de forma paladina que la Administración, con su omnipresente potestad reglamentaria y aun como formuladora de los proyectos de Ley, introduce con normalidad nuevas normas de cuya necesidad y aun de cuyo alcance real, por referencia a la regulación existente, ella misma no es ni siquiera consciente, y puede concluirse abora que ni siquiera le interesa serlo... como si la Administración viviese más cómodamente en un mundo de incertidumbre normativa» (GARCÍA DE ENTERRÍA, 1999: 97, tmb. pp. 77-78 y GONZÁLEZ ORDOVÁs, 2003: 95 y ss). 
dor español no sólo da por cerrado el proceso codificador y considera impertinentes las necesidades que pudiera satisfacer, sino que también está dispuesto a colaborar al mantenimiento de la actual situación legislativa. Así, y cogiendo la "crisis por los pelos", declara la asistematicidad, inestabilidad, generalización de la especialidad, olvido de la certeza y seguridad y descontrol de un legislativo entregado al ejecutivo y sometido a una fiscalización constitucional "cotidianizada".

Me parece que con bastante lógica y justicia esta opción pública española se ha ganado una frecuente crítica doctrinal por ir contra los principios básicos de racionalidad sistémica, claridad, sencillez, coherencia y seguridad jurídica ${ }^{49}$.

\section{CONCLUSIONES: ¿CODIFICAMOS DE NUEVAS O SEGUIMOS A LEGISLACIÓN DISPERSA?}

(23) El análisis previo ha rotado en torno a la necesidad y la posibilidad de abordar una neocodificación que mejore las condiciones del panorama normativo actual pero reforzando, rearticulando y racionalizando (no renunciando) las pertinentes condiciones político-materiales del Estado social de Derecho neoconstitucional.

Sabiendo que lo bueno que aún preserva la Utopía ilustrada se asfixia en manos del cierre, el centralismo y el formalismo ${ }^{50}$, la nueva alternativa codificadora, de un lado, debe apartarse de la dogmática vinculada a tradiciones construidas por el poder y de contratradiciones ajenas a las necesidades del escenario jurídico real y de consecuencias deconstructivas. Y, de otro lado, exige ser conscientes de la realidad social, política, legislativa, judicial, etc., abordando sus problemas y construyendo a tal efecto los instrumentos más apropiados de solución gracias a una teoría y técnica legislativas - racionalmente justificadas y fundamentadoras que sirven para encauzar el discurso político-social- y a los aportes de la experiencia comparada.

El objetivo del proyecto neocodificador debe ser "sistematizar" y "racionalizar" el escenario jurídico actual. Sistematizar es ofrecer un arquetipo estructural que exprese un orden interno, como si de un sistema de conjuntos se tratase. Y racionalizar es fundamentar, ofrecer razones justificadas. Como sistematizar la realidad jurídica positiva es apelar al orden interno que configura de forma excluyente la definición de validez/invalidez del Derecho, la sistematización codificadora se centra en la definición formal del Derecho. Sin embargo, la fuerza crítico-reconstructiva de tal proyecto depende de su capacidad para esclarecer la forma más adecuada de interrelación de los distintos elementos normativos y que sirve para mantener su consistencia interna formal. Por eso es imprescindible fundamentar esta sistematización, esto es, raciona-

49 En este sentido, p. ej., Cazorla Prieto, 1999: 43 y ss., Pau Pedrón, 1999: 75 y ss.

50 Pues «la codificación entendida en términos históricos y tradicionales, si no ha saltado por los aires hecha añicos, está cerca de ello» (CAZORLA PRIETO, 1999: 43) (complementariamente la propuesta de DE LOS Mozos, 2001: 5 y ss.). En otras palabras, «(1)as ilusiones codificadoras son utópicas, es decir, su relación con la realidad es falsa y está distorsionada... Su Utopismo se debe a que piensa las posibilidades instrumentales inherentes a la racionalización formal como hechos realizados, y como una realidad histórica trascendente» (VARGA, 1978: 37-38). 
lizarla. Pero ya no apelando a su consistencia estructural, sino al sentido racional teórico y práctico del sistema de codificación. Así, la racionalización, más que a la consistencia o a la lógica interna sistematizadora, apela a una forma de coherencia compleja que depende en amplia medida de criterios valorativos y de ponderación, porque se refiere a la fuerza de los argumentos en relación con los objetivos e instrumentos conforme a los que se estructuran.

La sistematización del material jurídico siempre depende del tipo de racionalización al que se apunte —y todo esfuerzo sistematizador, incluido el decimonónico, participa de su propio modelo de racionalidad-. Por eso cada arquetipo sistematizador no se justifica por sí mismo, ni sólo por el orden que anhela, sino por el carácter fundamentado de los criterios racionalizadores del sistema. Como parto, sin poder profundizar aquí en esto, de un modelo racional teóricamente fundamentado en una razón práctica articulada en clave discursiva, el sistema neocodificador se rediseña en favor de la diversidad y la apertura a múltiples centros sistémicos interconectados. Esto, desde la perspectiva externa descriptiva, da cuenta de una concepción plural del Derecho de la que hace tiempo los sociólogos advierten a los juristas. Pero también permite afrontar la diversidad conforme a estándar crítico-normativos que conducen a una fundamentación sistémica interna.

La sanción por la asistematicidad y por la sistematización no racionalizada teórica y prácticamente es el desorden y el caos normativo que, a su vez, conllevan la falta de incidencia. Porque a la existencia de una realidad policéntrica y de acrecimiento tuitivo estatal se añade la proliferación normativa derivada de la dimensión reactiva frente a esa realidad normativa ${ }^{51}$, «una reiteración reguladora frente a una reacción de rechazo del sector regulado» (RoIG, 2003: 106).

Por lo expuesto, apelar hoy a una neocodificación es reclamar la sistematización como instrumento al servicio del orden, la facilidad de acceso, la seguridad jurídica, la inteligibilidad, etc. Pero, eso sí, siempre que se trate de una sistematización segmentada por unos cánones racionalizadores renovados fieles a consideraciones valorativas fundamentadas y que, entre otras cosas, orienten a la concepción monosistémica de la codificación decimonónica al policentrismo material y orgánico, a un poli-sistema que refiera la existencia de múltiples centros normadores - legislativos, judiciales, doctrinales, sociales, etc.- que unifican su racionalidad en la visión del ordenamiento jurídico como un todo constitucional ${ }^{52}$.

(24) Este policentrismo no reconoce sólo la ampliación de fuentes formales en los sistemas jurídicos desarrollados por su diversificación interna y la apertura supranacional. También actualiza el pluralismo jurídico para colocar la definición del Derecho plural ante la pantalla del Derecho efectivamente practicado. A este respecto las teorías de "policentralidad legal" y de "acomodación legal" aportan instrumentos para

\footnotetext{
${ }^{51}$ Por ello, el mínimo que hay que comenzar exigiendo al Derecho es que configure su normatividad y legislación a partir de una verdadera voluntad de incidencia. Y ésta requiere tanto la coordinación y acoplamiento de las imágenes propias que cada subsistema social de significación posee (proponiendo retraducciones conceptuales internas del subsistema apropiadas al sistema normativo jurídico), cuanto la entrada en juego de la sociología y la política del Derecho, el estudio económico del Derecho, la comunicación con los sectores relevantes, etc., favoreciéndose un diálogo traducible a los propios elementos de cada sistema (TEUBNER).

52 En este sentido, IRTI, 1992: 190-191.
} 
reconstruir una concepción que describa mejor y que sirva a una visión crítico-constructiva fundamentada y de fundamentación ${ }^{53}$.

Si tomamos estos genéricos presupuestos como criterio con el que medir las razones de la actual impotencia, p. ej., de nuestro Código Civil, los resultados, lejos de sorprender, muestran cierta obviedad. Y es que el proceso de formación del generalizadamente reconocido como mediocre Código Civil español de 1889 desatendió la pluralidad material de los intereses sociales, la diversidad funcional de los centros de producción del Derecho y las exigencias de inteligibilidad del arquetipo formal ${ }^{54}$. Así, se convirtió en un Código abocado a revisión antes de su propia entrada en vigor y que exhibía mala técnica legislativa —inexactitud, tecnicismos, artículos de imposible aplicación, defectuosos por error u omisión, etc. ${ }^{55}$ - , desinterés social, individualismo, clasismo burgués frente al criado y el trabajador asalariado, concepciones familiares patriarcales y machistas, cesiones poco civiles al matrimonio católico, desatención a los Derechos forales, etc. Normal es, pues, que la aparición de un Código desfasado en origen alimentara las críticas anticodificadoras y, sobre todo, haya puesto a todos sobreaviso de nuevos afanes codificadores que podrían empeorar aún más el confuso panorama legal actual. (Claro que, teniendo en cuenta que su redacción se encargó a un grupo de varones burgueses ya ocupados en otros asuntos y que, en general, se escucharon sólo a sí mismos, que el discurso y la comunicación fallaron en los trabajos preparatorios y que el apresuramiento fue el colofón de Código, ni sus resultados ni las pertinentes críticas sorprenden).

Pero, en realidad, se hizo mal en general. Por eso todas las codificaciones voluntaristas y centralistas enseguida mostraron en las distintas sociedades su anomía social y hoy se ven sobrepasadas por la realidad legislativa y jurisdiccional. Esto exige hacer mejor las cosas; y un comienzo de mejora, decía, es articular la neocodificación en torno a la noción compleja de polisistema funcional y material y a una visión dinámica y comprehensiva del Derecho.

53 Con ellas, dicho sintéticamente, se vindica (policentralidad legal-ZAHLE): huida de los efectos centralizadores y totalizantes de la teoría al uso, renuncia a las concepciones del Derecho únicas, cerradas y plenas y que definen el Derecho por oposición a lo otro; análisis de la relación compleja de interacción entre las formas plurales de ordenación que participan en el mismo campo social y las formas legales de coexistencia de esas relaciones; activación de una concepción ética, orientada a la consecución de una pluralidad armónica en la que puedan ampararse los distintos reclamos de justicia; análisis de la naturaleza ideológica de los distintos sistemas normativos; análisis de la definición y reparto de autoridad para adoptar decisiones. De lo que se trata (acomodación legal-[DOYLE]) es de promover una concepción que dé sentido a un pluralismo respetuoso de la individualidad y de las especifidades de los distintos grupos de interés. Pero los grupos de interés no pueden seguir centrándose en definiciones culturales y/o tradicionales de los mismos, sino que se especifican a partir de la definición de cada grupo de individuos de sus afinidades y sus consiguientes intereses y necesidades. Por eso, la propuesta es «establecer el mecanismo político-jurídico apropiado a la existencia social de esos distintos grupos de afinidades... (H)uye de la asimilación, la segregación, el aislacionismo, la marginación o la subordinación... a favor de la proclamación sustantiva del derecho de los miembros y los distintos grupos de afinidad de estar representados en la deliberación pública y la toma de decisiones políticas y en las organizaciones privadas» (SUÁREZ LLANOS). Ya en otro lugar me ocupé de analizar y valorar más pormenorizadamente ambas concepciones y la propuesta convencionalista en sus esfuerzos por viabilizar el concepto de pluralismo jurídico; en SUÁREZ LLANOS, 2004: 15-57.

54 El resultado fue un Código apresurado, que ni miró a su alrededor para ver «las necesidades y progresos del tiempo... las necesidades sociales del día y... ciertas ineludibles previsiones que una ley de esta índole no debiera omitir... varios, y aun muchos artículos del Código deberían corregirse» (informe de la Comisión del Senado).

55 Complementariamente, De Buen, 1977: 170 y ss. 
(25) Este proyecto, sin duda, permite intentar muchas cosas y unas saldrán mejor que otras. Al respecto, me limitaré a sintetizar algunas líneas generales.

En primer lugar, la neocodificación debe concebirse en el marco de una teoría de la legislación de fundamentación discursivo-consensual, lo que sirve a la exigencia racionalizadora de la sistematización que se proponga. Así, se incide sobre y se vindica el hecho práctico de que aunque el Derecho es un orden positivo distinto al estándar de lo moral, natural, etc. — pues la ley se cualifica como tal indepedientemente de lo que podamos creer sus méritos o deméritos-; sin embargo, en los Estados desarrollados, el Derecho ya no es un mero orden voluntarista de coacción ${ }^{56}$ ya que las consideraciones sobre la corrección material del Derecho se convierten de hecho, y deben convertirse en el nivel de justificación, en criterios operativos de validez.

Esto exige atender a una comprensión compleja, comprehensiva y dinámica del Derecho en busca de una sistematización y clarificación del mismo acorde con los valores constitucionales, los ideales políticos liberales de libertad, derechos, limitación pública de la actuación estatal, interdicción de la arbitrariedad, responsabilidad y seguridad jurídica respecto de la legalidad y las decisiones aplicativas de la misma. Tal planteamiento aboca una "concepción reflexiva" del Derecho en la que la perspectiva normativa se complementa con una visión constitucional que actualiza una comprensión relacional que transforma al Derecho en un escáner de la regulación social. Esto permitirá, de un lado, la institucionalización ordenada de una concepción pluralista de las fuentes del Derecho. Y, de otro, la "rematerialización" del Derecho que tanto se impone en su pragmática constitutiva cuanto debe ser orientada por la teoría crítica fundamentadora a una racionalidad sustantiva (en amplia medida procedimental). Pues la fundamentación discursiva se sirve de una razón práctica que nos advierte de que la igualdad en los derechos y garantías no depende de una igualitaria distribución de bienes, sino de un derecho igualitario a participar en los procesos distributivos negociando los derechos propios ${ }^{57}$. De esta forma, se acercaría la "verdad procedimental" a la "verdad material".

En segundo lugar, hay que considerar seriamente la propuesta de deslindar las materias más propias de una legislación de otras que exigen una normación más detallada o admiten una regulación plural. Tanto por descargar la realidad hiperlegislada, vista desde una perspectiva estática, cuanto por enfrentar la importante causa de inflación legislativa que supone el rechazo normativo y la fluctuación de leyes al albur de las políticas gubernamentales particulares, y además porque se facilitaría el sentido de la ordenación en su conjunto. «Al respecto importa tener presente que el legislador ha mostrado un exceso en el mundo moderno con una arrogante monopolización de lo jurídico... haciéndolo, ha demostrado también su impotencia» (GROssI, 2003: 92). Y también que, aunque la acción normativa del gobierno es constitucional y legítima, llega a servirse de figuras que, en su esfuerzo por abarcar el mayor ámbito material posible, se mueven por los lindes de lo inaceptable (leyes de caso único, abuso de

${ }^{56}$ Véase complementariamente SIMMONDS, 2005: 266 y ss.

57 En esta línea, Preuss, 1986: 170, Habermas, 1998: 502 y ss. Y es que «(l)a justicia debería referirse no solamente a la distribución, sino también a las condiciones institucionales necesarias para el desarrollo y ejercicio de las capacidades individuales y de la comunicación y cooperación colectivas» (YounG, 1990: 39). 
legislación singular, leyes de acompañamiento materialmente desbordadas, etc.). En este sentido, el deslinde dinámico caracterizaría ciertos sectores como más apropiados de regulaciones concretas y cambiantes animadas por el gobierno y otros núcleos sociales representativos de intereses, «abandonando la desconfianza ilustrada hacia la sociedad». Y la ley quedaría, respecto de estas materias, encargada de establecer los principios y criterios generales positivos que deben guiar y engarzar tal práctica normativa y que serían más fácilmente reconducibles a, y sistematizables en, el marco codificado, aspecto este de interés por lo que se refiere a la legislación especial ${ }^{58}$ que debería insertarse sistémica, razonable, clara y adecuadamente en el conjunto ${ }^{59}$.

En tercer lugar, me parece importante remover la idea de que una Comisión de Codificación, o cualquier otro órgano paralelo, concreta y agota su función en la preservación de las codificaciones existentes. Pues aunque su cometido no es sustituir al legislador, sí debe sistematizar las normas por conjuntos homogéneos, esclarecer y actualizar su lenguaje conforme a las claves de técnica legislativa ${ }^{60}$ que trasladan el sentido efectivo de la comunicación jurídica que conforma el Derecho, y también proponer su reordenación y redefinición atendiendo a una visión compleja y dinámica del sistema jurídico que desplaza su centro legicéntrico para hacerle recorrer los distintos focos normativos, interpretativos, de interés y de sentido de la legislación. Entonces ya sí se hará cierto que «el código es el futuro de la ley». En este marco encaja bien el reclamo doctrinal de emprender una segunda codificación en España que, entre otras cosas, garantice la agilidad y una amplia colaboración entre el Gobierno y otras instancias como los Ministerios, el Consejo de Estado, el Consejo General del Poder Judicial, el Consejo Económico y Social, el Tribunal Constitucional, etc., evitándose sobrecargar el trabajo parlamentario ${ }^{61}$.

58 Si bien el marco de disposiciones y garantías constitucionales de naturaleza formal y también sustantiva no puede ser burlado por el legislador. Por lo que resultaría tan inaceptable que se deslegalicen materias legales incontroladamente como abocar una legislación "capilar" especial incontrolada (CAZORLA PRIETO).

${ }_{59}$ Perspectiva ratificada por el TC español, p. ej., al extender la condición de código a la Ley General Tributaria.

${ }^{60}$ Para la mejora de la técnica legislativa se aprueba la Resolución de la Subsecretaría de la Presidencia del Gobierno, de 6 de noviembre de 1995, en la que se propone la creación, a partir de la actual Comisión General de Codificación, de un Órgano Central de Codificación encargado del estudio e iniciativa respecto de los anteproyectos de ley para su aprobación y elevación al Gobierno de la nación, lo que debe ponerse en relación con el Acuerdo del Consejo de Ministros de 18 de octubre de 1991 «por el que se aprueban las directrices sobre la forma y estructura de los anteproyectos de ley» derogado por la Resolución de 28 de julio del 2005 que aprueba las nuevas Directrices de técnica normativa y que tiene un ámbito material de aplicación más amplio. Ese órgano se encargaría de: preparar los anteproyectos de ley para las materias reguladas de los códigos y las disposiciones básicas del Estado; consolidar periódicamente las grandes leyes generales mediante textos refundidos o mediante leyes consolidadas aprobadas por las Cortes Generales; realizar un seguimiento de los trabajos de la Unión Europea en relación con las materias reguladas en los Códigos y las disposiciones generales; realizar un seguimiento de las leyes de carácter general dictadas por las CC.AA. para fijar su relación con las leyes generales del Estado y preparar, de ser necesario, las modificaciones legales oportunas a nivel estatal o el planteamiento de cuestiones de inconstitucionalidad. (Véase, al respecto, CAzorLa PrieTo, 1999: 75-81; SEBASTIÁN LORENTE, 1997: 1197 y ss.).

${ }^{61}$ MenÉnDEZ apunta algunas medidas esenciales de reforma de la Comisión de Codificación para capacitarla frente a los nuevos retos del Derecho: que sea presidida por un miembro representativo de la comunidad científica o académica y dedicado en exclusiva a la Comisión; que se integre por juristas de reconocido prestigio; que su trabajo se distribuya en régimen de ponencias en las distintas Secciones con posterior intervención en el Pleno de la Sección; que se reformule su competencia como mero órgano conservador de los Códigos existentes; que se replantee la función del Ministerio de Justicia, al que se subordina, como órgano 
Para poner en marcha este proyecto se podría concebir a la Comisión General de Codificación más bien, o también, como un órgano que actúe en el marco del a veces reclamado Consejo General de Legislación — cuestionándose la subordinación orgánica y funcional de nuestra Comisión de Codificación al Ministerio de Justicia- que no se asimilaría a lo que en España entendemos por Consejo de Estado, a pesar de su labor informante y de cuidado de técnica legislativa, sino que poseería la relevancia y autonomía funcional necesaria para encauzar un procedimiento legislativo de consolidación y esclarecimiento acorde con los presupuestos discursivos, constitucionales y de fundamentación, y que colaboraría permanentemente — «con suficientes medios materiales, una organización personal adecuada... el apoyo de otras instituciones y la conexión oportuna con los órganos políticos y legislativos» (MENÉNDEZ, 1999: 28)— en la actividad legislativa para evitar los obstáculos que para la racionalización legislativa representan las deformaciones partidistas y el exceso normativo legislativo de los gobiernos.

Cuarto, la nueva fórmula codificadora no debe preajustarse a límites rígidamente formalizados, ya que el sentido que la anima obliga a contemplar la regulación como una pugna por el poder entre distintos grupos que no puede estancarse bajo excusas clausurantes ${ }^{62}$. Por eso, debería atender a un modelo sistemático pero parcelado temáticamente conforme a cláusulas de razonabilidad, no de adscripción ministerial, y a los objetivos de claridad para los usuarios al ser instrumentos básicos de conocimiento de las reglas que rigen la actuación judicial y condicionan la actividad de los ciudadanos.

En quinto lugar, la actividad neocodificadora debe: $i$ ) tender un puente a la actividad judicial más significativa proponiendo una clarificación positiva, pero no estática, del significado de los principios en relación con las leyes, y ii) atender permanente a las construcciones teóricas para buscar una mayor racionalización del sistema y de la coherencia de la normación positiva. Al respecto, los trabajos preparatorios y tentativos, de lege lata y con finalidad orientativa, serían el primer estadio de reorganización de la praxis desde el que después se puede recomendar el paso último de la supervisión, modificación en su caso y aprobación parlamentaria.

$\mathrm{Al}$ abordar este proyecto complejo de neocodificación nos percataremos de que «todavía nos faltan instrumentos para afrontar de manera racional, sistemática y satisfactoria la complejidad de las situaciones jurídicas» (ARNAUD), pero se estarán dando pasos fundamentales para la racionalización de la «pragmática del conflicto», al garantizarse que las instituciones estatales dirigen su mirada a la sociedad dividida y a la realidad policéntrica del Derecho en un esfuerzo por materializar la exigencia de publicidad y transparencia democrática — refiriéndose a la elaboración, identificación, aplicación, interpretación y caracterización del Derecho.

Finalmente, sexto, es importante tener presente que un proyecto neocodificador en un marco neoconstitucional como el actual exige estar permanentemente alerta

promotor del Derecho; que se aporten estudios estadísticos, económicos y sociológicos para que las leyes dejen de ser intuitivas; que se incentive la comunicación permanente entre órganos administrativos y legislativos (MENÉNDEZ, 1999: 27-27; tmb. 18-21).

${ }^{62}$ Complementariamente, IRTI, 1992: 35-41. 
frente a los riesgos de esclereotización y tecnocratización de las nuevas codificaciones. Porque, de un lado, no se pretende inmovilizar cualquier posibilidad de cambio, sino de frenar la creación explosiva, reforma permanente, desencaje, banalización, incorrección, oscuridad, contradicción... de los textos legales y la irrestricta discrecionalidad judicial que animan. $\mathrm{Y}$ es que «(n)o se trata sólo de un problema de comodidad material sino de claridad jurídica. La codificación facilita la reforma en lugar de entorpecerla» ${ }^{63}$ (BRAIBANT, 1999: 94). Y porque, de otro lado, aunque el nuevo agente de una nueva codificación de lege lata y a Derecho constante en amplia medida sean técnicos y especialistas en diversas materias, esto no tiene por qué significar tecnocratización del sentido político de la ley, de hecho la tecnocratización se multiplica con la dispersión, multiplicación y fragmentariedad legislativa. Mientras que lo que ahora se precisa es contraer aquel expansivo fenómeno gracias a la integración de perspectivas diversas que ordenen la realidad legislativa y la práctica judicial subordinándolas a la importante función a la que sirven: garantizar el sentido de la motivación judicial, el sentido de la ignorancia no eximente, el postulado democrático del Derecho del pueblo, reforzar la seguridad jurídica y, con todo ello, ampliar el proyecto liberal de protección de los derechos, libertades y garantías de los ciudadanos.

\section{BIBLIOGRAFÍA CITADA}

Albiez Dohrmann, K. J., 2003: «La integración del Derecho de consumo contractual en el Código Civil: ¿una simple entelequia jurídica o algo más?», Estudios Jurídicos en Homenaje al Profesor Luis Díez-Picazo, Madrid: Thomson, Civitas.

Alejandre García, J. A., 1980: Derecho del Constitucionalismo y de la Codificación, Universidad de Sevilla.

Álvarez Alonso, C., 2003: «La legitimación del sistema. Legisladores, jueces y juristas en España (1810-1870)», Revista Electrónica de Derecho Constitucional, 4.

Atienza, M., 1997: Contribución a una Teoría de la Legislación, Madrid: Civitas.

Attias, C., 1999: Le Code civil nouveau, Dalloz.

Braibant, G., 1999: «El modelo francés de la nueva codificación», Seguridad Jurídica y Codificación, Madrid: Centro de Estudios Registrales.

BurT, R., 1995: The Constitution in Conflict, Harvard Univ. Press.

CaÑIZAREs LASO, A., 2003: «La prescripción en el BGB después de la reforma del Derecho de obligaciones», Estudios Jurídicos en Homenaje al Profesor Luis Diez-Picazo, Madrid: Thomson, Civitas.

CarnelutTI, F., 1953a: «La crisi del Diritto», Discorsi intorno al Diritto, vol. II.

- 1953b: «La morte del Diritto», Discorsi intorno al Diritto, vol. II.

- 1953c: «Nuove riflessioni intorno alla certezza del Diritto», Discorsi intorno al Diritto, vol. II.

Cazorla Prieto, L. M. ${ }^{a}, 1999$ : «La codificación como función de los poderes públicos. El caso español», Seguridad Jurídica y Codificación, Madrid: Centro de Estudios Registrales.

${ }^{63}$ Si se prefiere, que la nueva codificación «en nada se opone - al contrario, prepara - una posible reforma posterior; el hecho de que aquellos textos se ordenen y sistematicen no supone, en sí mismo, ningún propósito de fijación o estabilización de su contenido. Esta segunda codificación no tiene como fin la permanencia del fondo, pero sí la permanencia de la forma — de la nueva estructura global— (PAU PEDRÓN, 1999: 83). 
CuRzon, L. B., 1995: Jurisprudence, London: Cavendish.

Dainow, D., 1954: «Le droit civil de la Louisianie», Revue Internationel de Droit Comparé, n. ${ }^{\circ} 6$.

De Buen, D., 1977: Introducción al Estudio del Derecho Civil. Ideas Generales. Fuentes Históricas del Derecho Civil Español. Codificación. Normas Jurídicas, Argentina: Porrúa.

De Los Mozos, 1988: «Los precedentes de la codificación: la unificación del Derecho en los propósitos de la Ilustración española», Anuario de Drecho Civil, vol. LXI (III).

— 2001: «Codificación y recodificación: reflexiones con motivo de la reforma del Código Civil peruano», Revista General de Legislación y Jurisprudencia, n. ${ }^{\circ} 11$.

DíEZ-PiCAZO, L., 1992: «Codificación, descodificación y recodificación», $A D C$, vol. XLV.

Doyle, J. F., 1998: «Legal accomodation an social diversity», Rechtstheorie, vol. 18.

Ferrajoli, L., 2004: Derechos y Garantías. La Ley del más Débil, Trotta.

- 2001: El Garantismo y la Filosofía del Derecho, Universidad Externado de Colombia.

GarCíA DE EnTERríA, E., 1999: Justicia y seguridad jurídicas en un mundo de leyes desbocadas, Madrid: Civitas.

Gény, F., 2000: Método y Fuentes en Derecho Privado y Positivo, Granada: Comares.

GonZÁlez Ordovás, M. a J., 2003: Ineficacia, Anomia y Fuentes del Derecho, (Cuadernos «Bartolomé de las Casas», 28), Madrid: Dykinson.

Grossi, P., 2003: Mitología Jurídica de la Modernidad, Madrid: Trotta.

Habermas, J., 1998: Facticidad y Validez, Madrid: Trotta.

Hart JR., H. M., y SAcks, A. M., 1994: The Legal Process. Basic Problems in the Making and Application of Law, New York: Foundation Press.

Heck, P., 1999: El Problema de la Creación del Derecho, Granada: Comares.

Horkheimer, M., y Adorno, T. W., 1994: Dialéctica de la Ilustración, Madrid: Trotta.

IHERING, R., 1961: El Fin en el Derecho, México: Cagica.

- 1987: «Cartas sobre la jurisprudencia actual», Bromas y Veras en la Jurisprudencia, Madrid: Civitas.

IRTI, N., 1992: La Edad de la Descodificación, Barcelona: Bosch.

Kantorowicz, H., 1949: «La lucha por la ciencia del Derecho», La Ciencia del Derecho, Buenos Aires: Losada.

LA TORRE, M., 1993: «Derecho y conceptos de Derecho. Tendencias evolutivas desde una perspectiva europea», Revista del Centro de Estudios Constitucionales, n. ${ }^{\circ} 16$.

- 1994: «Formalism and anti-formalism in Modern-State Law and beyond», Prescriptive formality and Normative Rationality in Modern Legal Systems, Berlin: Duncker \& Humbloy.

LASSERRE-KIESOW, V., 2005: «L'esprit scientifique du Code Civil», Droits, n. ${ }^{\circ} 41$.

LEE, K., 1990: The Legal Rational State, Newcastle: Avebury.

LuCAS Verdú, 1987: La Lucha contra el Positivismo Jurídico en la República de Weimar, Madrid: Tecnos.

Luhmann, N., 2002: El Derecho de la Sociedad, México: Universidad Iberoamericana.

Mangabeira Unger, R., 1985: Conocimiento y Política, México: Fondo de Cultura Económica.

Marcilla Córdoba, G., 2005: Racionalidad Legislativa. Crisis de la Ley y Nueva Ciencia de la Legislación, Madrid: Centro de Estudios Políticos y Constitucionales.

MENÉnDEZ, A., 1999: «La Comisión General de Codificación y la elaboración de las leyes», Seguridad Jurídica y Codificación, Madrid: Centro de Estudios Registrales.

Montilla, A., 1987: «La codificación como técnica de producción legislativa», Revista de Derecho Privado, vol. LXXI. 
Orduña Moreno, F. J., 2003: «El influjo del Derecho privado europeo en la metodología del Código Civil», Estudios Jurídicos en Homenaje al Profesor Luis Díaz-Picazo, Madrid: Thomson, Civitas.

Pau Pedrón, A., 1999: «La segunda codificación», Seguridad Jurídica y Codificación, Madrid: Centro de Estudios Registrales.

Preuss, U. K., 1986: «The concept of rigths and the welfare state», Dilemmas of Law in the Welfare State, Berlin: Walter de Gruyter.

Prieto SAnchís, L., 1998: «Del mito a la decadencia de la ley. La ley en el Estado constitucional», Ley, Principios, Derechos, Dykinson.

- 1999: Constitucionalismo y Positivismo, México: Fontamara (BFDP).

Ramos NúÑEZ, C., 2000: «La codificación: impulso moderno de la familia romanista», Derecho E Sociedad, n. ${ }^{\text {os }} 8-9$.

Rivera, J. C., 1998: Instituciones de Derecho Civil, Madrid: Bs. As.

RoIG, A., 2003: La Deslegalización. Orígenes y Limites Constitucionales en Francia, Italia y España, Madrid: Dykinson.

ROMÁN GARCÍA, A. M., 2003: «Codificación, descodificación y recodificación en el Derecho Civil», Estudios Jurídicos en Homenaje al Profesor Luis Díaz-Picazo, Madrid: Thomson, Civitas.

Rubio Llorente, F., 1990: «El juez y la ley desde el punto de vista del principio de igualdad», El Poder Judicial en el Bicentenario de la Revolución Francesa, Madrid: Ministerio Justicia.

SAmuel, G., 2005: L'esprit de non-codification: Le Common Law face au Code Napoléon», Droits, n. ${ }^{\circ} 41$.

Sebastián LoREnTE, J. J., 1997: «La Comisión General de Codificación. De órgano colegislador a órgano asesor», Actualidad Civil, n. ${ }^{\circ} 47$.

Simmonds, N. E., 2005: «Jurisprudence as a moral and historical inquiry», The Canadian Journal of Law E Jurisprudence, n. ${ }^{\circ} 2$, vol. XVIII.

SuÁrez LlanOS, L., 2004: «La "cultura jurídica” y el "pluralismo jurídico”. Problemas de definición», BFD, n. ${ }^{\circ} 24$.

VARGA, C., 1978: «Utopias of rationality in the development of the idea of codification», RIFD, LV-1.

VARGAS MuÑOZ, J. M. de, 2003: «La codificación civil: breve referencia a sus bases socioeconómicas y filosófico-jurídicas», Estudios Jurídicos en Homenaje al Profesor Díaz-Picazo, Madrid: Civitas, Thomson.

TARello, G., 1976: Storia della Cultura Giuridica Moderna, Bologna: Il Mulino.

- 1995. Cultura Jurídica y Política del Derecho, Fondo de Cultura Económica.

Tunc, A., y Tunc, S., 1957: El Derecho de los Estados Unidos de América: Instituciones Judiciales, Fuentes y Técnicas, Imp. Univ. México.

WIECKeR, F., 1952: Historia del Derecho Privado Moderno, Madrid: Aguilar.

Young, I. M., 1990: Justice and the Politics of Difference, Princenton.

Zagrebelsky, G., 2003: El Derecho dúctil. Ley, Derechos, Justicia, Madrid: Trotta. 